\title{
Proton Pump Inhibitor Therapy for Eosinophilic Esophagitis: History, Mechanisms, Efficacy, and Future Directions
}

\author{
James P Franciosi $\mathbb{D}^{1,2}$, Edward B Mougey ${ }^{3}$, Evan S Dellon ${ }^{4}$, Carolina Gutierrez-Junquera $\mathbb{D}^{5}$, \\ Sonia Fernandez-Fernandez ${ }^{6}$, Rajitha D Venkatesh ${ }^{7}$, Sandeep K Gupta ${ }^{8}$ \\ 'Division of Gastroenterology, Nemours Children's Hospital, Orlando, FL, USA; ${ }^{2}$ College of Medicine, University of Central Florida, Orlando, FL, \\ USA; ${ }^{3}$ Center for Pharmacogenomics and Translational Research, Nemours Children's Health System, Jacksonville, FL, USA; ${ }^{4}$ Center for Esophageal \\ Diseases and Swallowing, Division of Gastroenterology and Hepatology, University of North Carolina School of Medicine, Chapel Hill, NC, USA; \\ ${ }^{5}$ Pediatric Gastroenterology Unit, Hospital Universitario Puerta de Hierro-Majadahonda, Autonomous University of Madrid, Madrid, Spain; ${ }^{6}$ Pediatric \\ Gastroenterology Unit, Hospital Universitario Severo Ochoa, Madrid, Spain; ${ }^{7}$ Division of Pediatric Gastroenterology, Hepatology, and Nutrition, \\ Nationwide Children's Hospital, Columbus, OH, USA; ${ }^{8}$ Section of Pediatric Gastroenterology, Hepatology and Nutrition, Riley Hospital for Children, \\ Indiana University School of Medicine and Community Health Network, Indianapolis, IN, USA
}

Correspondence: James P Franciosi, Division of Gastroenterology, Nemours Children's Hospital, 6535 Nemours Parkway, Orlando, FL, 32827, USA, Tel +I 407567 3832; +I 407335 9908, Email james.franciosi@nemours.org

\begin{abstract}
Over the past decade, the role of proton pump inhibitor (PPI) medication has evolved from a diagnostic tool for Eosinophilic Esophagitis (EoE), by excluding patients with PPI responsive esophageal eosinophilia (PPI-REE), to a therapy for EoE. This transition resulted from the Updated International Consensus Diagnostic Criteria for Eosinophilic Esophagitis: Proceedings of the Appraisal of Guidelines for Research and Evaluation II (AGREE) Conference to support PPI therapy for EoE in children and adults. Additional recent advances have suggested a role for genetic variations that might impact response to PPI therapy for EoE. This review article will explore a brief background of EoE, the evolution of PPI therapy for EoE and its proposed mechanisms, efficacy and safety in children and adults, and considerations for future PPI precision medicine in patients with EoE.
\end{abstract}

Keywords: eosinophilic esophagitis, EoE, proton pump inhibitor medication, PPI, precision medicine

\section{EoE Background}

EoE is a chronic antigen-mediated inflammatory disease of the esophagus that affects both children and adults (Figure 1). ${ }^{4}$ It is a clinicopathologic disorder requiring a constellation of clinical and histologic findings (at least 15 eosinophils/high-powered microscope field (eos/hpf)) to establish the diagnosis, while excluding other etiologies of esophageal eosinophilia. ${ }^{1}$ The incidence and prevalence of EoE are rapidly rising as described in several populationbased studies from the United States and Europe with an estimated incidence of 6.6 per 100,000 person-years (95\% CI, $3-11.7$ ) in children and 7.7 per 100,000 person-years (95\% CI, 1.8-17.8) in adults. ${ }^{5}$ Esophageal dysfunction in EoE may present differently in children and adults. Infants and young children typically present with feeding difficulty, poor growth, abdominal pain, and vomiting while older children and adults present with dysphagia and esophageal food impaction. Patients with EoE may have a personal history of atopic conditions such as asthma, allergic rhinitis, allergic conjunctivitis and IgE mediated food allergies. Although EoE does not demonstrate classic Mendelian inheritance, there can be a genetic component to the condition in some patients, and a familial history of EoE increases individual risk compared to the general population. ${ }^{6}$ Inflammation in EoE is thought to result from penetration of the esophageal mucosa by food or aeroantigens resulting in a T-helper type $2\left(\mathrm{~T}_{\mathrm{h}} 2\right)$ cellular response and symptoms of esophageal dysfunction. ${ }^{7}$

The gold standard for EoE diagnosis remains demonstration of an increased intraepithelial esophageal eosinophil count by histology. ${ }^{8}$ Endoscopic examination and esophageal biopsies can be accomplished through esophagogastroduodenoscopy (EGD) ${ }^{9}$ or transnasal endoscopy (TNE).$^{10}$ If left untreated or when the patient is unresponsive to therapy, 


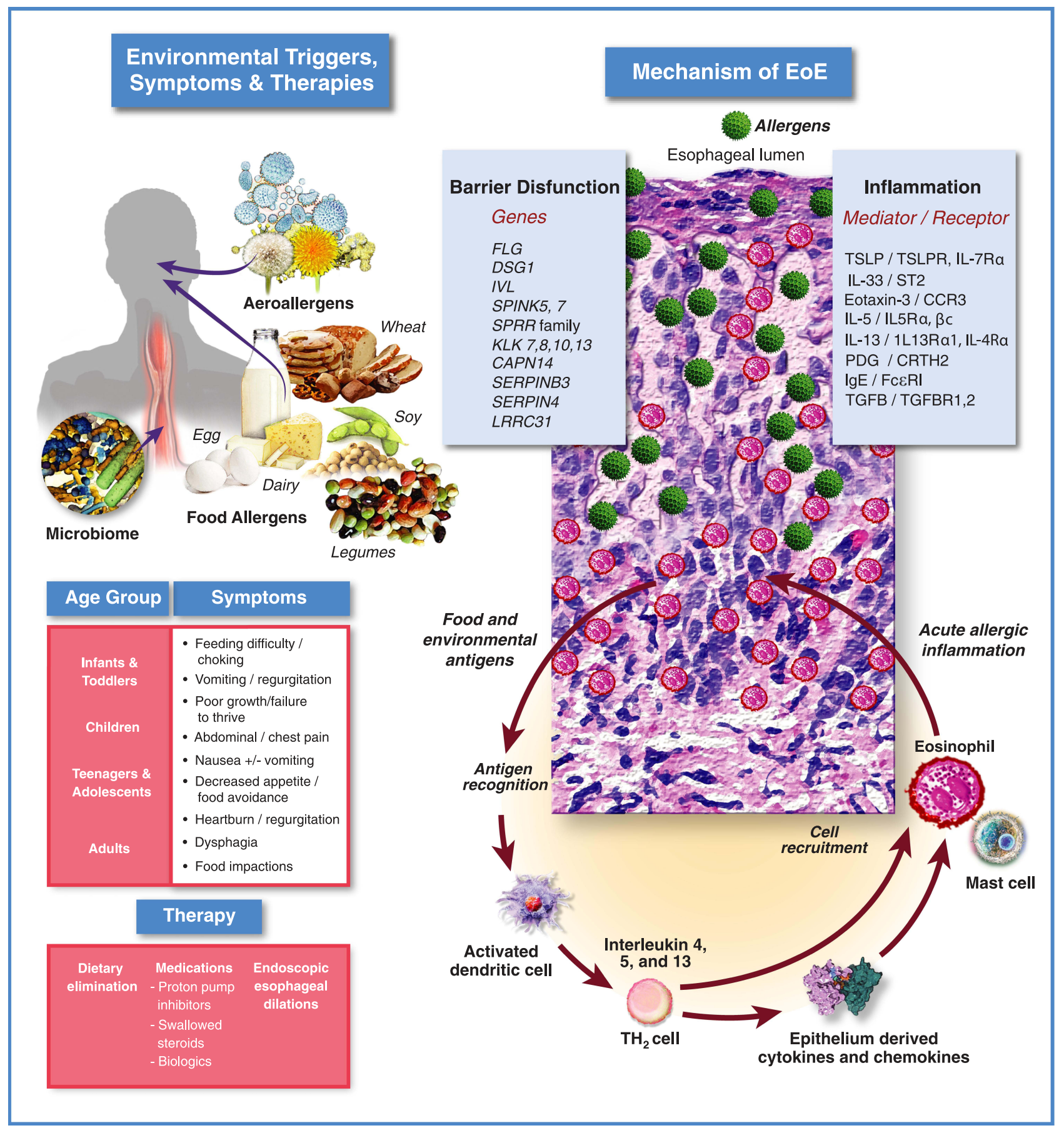

Figure I Eosinophilic esophagitis: clinical \& pathophysiologic overview.

Notes: Top Left: Major known environmental triggers of EoE include most commonly food allergens (ie, dairy, wheat, egg, soy and legumes) and to a lesser extent, aeroallergens (eg, pollen). Recently, a role for the gut microbiome in inception and/or severity of EoE has been proposed. ${ }^{209}$ Middle Left: EoE symptoms by age group. Bottom left: The three main classes of EoE therapies: I.) diet modification, ie, elimination diets; 2.) medications including proton pump inhibitors, topical swallowed corticosteroids, and biologics; 3.) endoscopic dilation. Upper right: EoE pathophysiology current understanding. A breach in the integrity of the esophageal epithelium, potentially facilitated by gastric acid exposure and/or carriage of genetic variants that compromise epithelial barrier function, allows ingress of food or aeroallergens (green spheres) leading to initiation of an immune response. Dilated intercellular spaces seen in biopsies of esophageal epithelium are a hallmark of EoE and tend to reflect disease severity. Interleukins produced by activated $\mathrm{T}_{\mathrm{h}} 2$ cells can act directly to recruit eosinophils to the esophagus (IL-5, red/pink cells), or can stimulate the epithelium to express inflammatory genes (IL-4/IL-13), including eotaxin-3, by activation of cell surface receptors that signal through a pathway involving JAKs and STAT6. Eotaxin-3 produced by the epithelium is a powerful chemotactic factor for eosinophils which are then recruited to the esophageal epithelium to propagate the inflammatory response. Mast cells also play a role in the inflammatory response that continues to be an active area of research investigation. 
EoE can progress to esophageal remodeling, luminal narrowing, and strictures. ${ }^{11,12}$ The treatment goals for EoE, while centered around resolution of esophageal eosinophilia, should also consider reversal of other histologic abnormalities and improvement in clinical symptoms, endoscopic improvement, as well as prevention of disease progression and subsequent complications. ${ }^{6}$ Standard treatment modalities include dietary modifications, esophageal dilation, and pharmacological therapy. ${ }^{7}$ However, pharmacology therapy is mainly off-label use as there is currently only one European Medicines Agency (EMA) approved medication (orodispersible budesonide tablets) and no FDA approved medications for the treatment of EoE.

\section{PPIs in EoE: From Diagnostic Criterion to a Primary Therapeutic Option}

The historical perspective of PPI therapy for EoE closely aligns with changing perspectives on esophageal eosinophilic inflammation over the past two decades (Figure 2). Prior to the 1990s, increasing eosinophilia on esophageal mucosal biopsies would be interpreted as worsening gastro-esophageal reflux disease (GERD) or GERD refractory to medical therapy, even with normal intra-esophageal $\mathrm{pH}$ monitoring over 24 hours ( $\mathrm{pH}$ probe) testing.

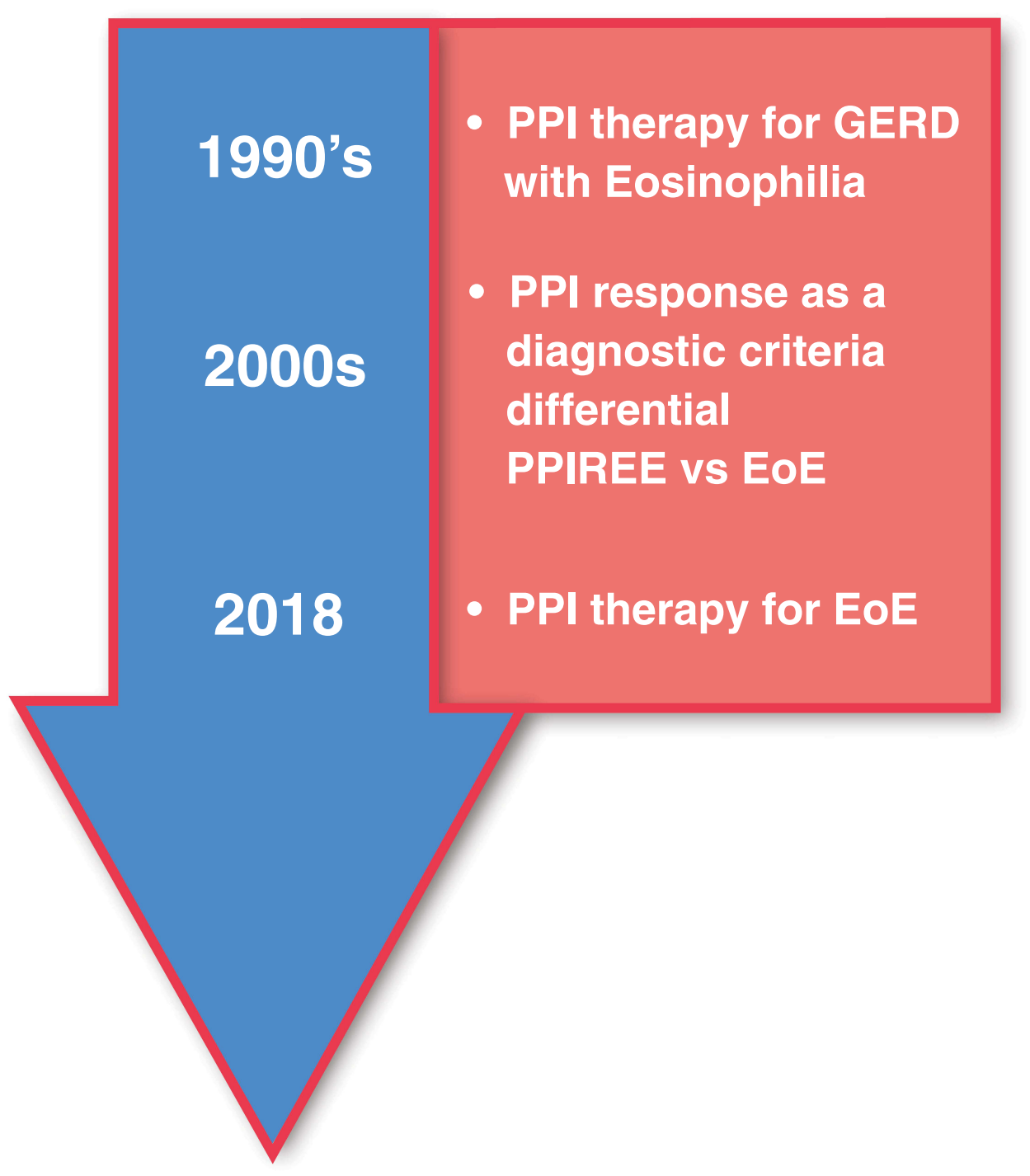

Figure 2 Progression of PPI therapy from diagnostic tool to therapy for EoE. Initial belief that EoE was a consequence of GERD led to early interest in PPIs as a therapy for EoE. Next, it was hypothesized that PPI-responsive esophageal eosinophilia (PPI-REE) was a condition distinct from EoE. A lack of response to PPIs was subsequently viewed as an essential diagnostic criterion for EoE. Subsequently, characterizations of PPI-REE and EoE patients at the molecular level showed that the two conditions are virtually identical leading to the hypothesis that they are at different points along a continuum. Recent guidelines, enlightened by this observation, now view PPIs as a therapy rather than a diagnostic for EoE. 
In the early 1990's, Attwood et al described 12 adult patients identified over a two-year period who presented with dysphagia without evidence of anatomical obstruction but with $>20$ eos/hpf in esophageal biopsies. ${ }^{13}$ Eleven of the 12 patients had normal esophageal acid exposure on $\mathrm{pH}$ probe, and 10 of the 12 patients showed evidence of a nonspecific motility disorder. They concluded that patients with this constellation of symptoms represented a distinct clinicopathologic syndrome not previously described. A year later, Straumann et al described 10 patients with identical symptoms and concluded that the prevalence of this "idiopathic eosinophilic esophagitis" was underestimated and may be the most frequent form of eosinophilic gastroenteropathy. ${ }^{14}$ Straumann also recognized the importance of prompt diagnosis and treatment with corticosteroids and antihistamines to avoid further diagnostic procedures associated with disease progression. In a study conducted in 1995 on a cohort of children, some of whom had undergone Nissen fundoplication for what was thought to be unremitting GERD, reversal of symptoms and esophageal mucosal eosinophilic inflammation was achieved following adherence to a free amino acid formula-based diet. ${ }^{15}$ Thereafter, the practicing community, especially in pediatric GI, began classifying esophageal eosinophilia into distinct acid-mediated or allergen/antigen-driven categories based on the number of eosinophils per high power field (eos/hpf) on esophageal mucosal biopsies. Two important papers facilitated the management of these patients - one in 1998 by Liacouras et $\mathrm{al}^{16}$ on the use of prednisone, and another a few months later on the use of swallowed topical corticosteroids ${ }^{17}$ for what was then being called eosinophilic esophagitis or allergic eosinophilic esophagitis or idiopathic eosinophilic esophagitis.

Prior to 2007, when the first consensus guidelines for EoE management were published, ${ }^{8}$ diagnostic criteria for EoE were not standardized, there was no uniform approach to PPI use, and there was substantial variability in the literature and in approaches to diagnosis. ${ }^{18}$ Interestingly, around the same time, Ngo et al ${ }^{19}$ published a case series of three patients with EoE who responded to PPI monotherapy (dose between 1 and $2 \mathrm{mg} / \mathrm{kg} / \mathrm{day}$ ). This observation was solidified by two retrospective pediatric studies showing that response to PPI therapy was common, seen in $40 \%$ of patients with symptomatic esophageal eosinophilia suggestive of $\mathrm{EoE},{ }^{20,21}$ and not necessarily dependent on results of pH probe studies. One study reported that about $50 \%$ of adults with suspected EoE responded histologically to PPI. ${ }^{22}$ The data further suggested an overlap between GERD and EoE: $20 \%$ of patients with an abnormal reflux index on pH probe did not achieve histologic remission on high-dose PPI therapy. Conversely, PPIs induced remission in 33\% of patients with normal $\mathrm{pH}$ probe results. Even though failure to induce remission of eosinophilic inflammation following treatment with PPIs was still considered a diagnostic criterion for EoE in the 2011 and 2013 guidelines, ${ }^{23,24}$ the discussion began shifting. In addition, the term PPI responsive esophageal eosinophilia (PPI-REE) was coined to denote patients who had $\geq 15$ eos/hpf on esophageal mucosal biopsies but responded histologically to high-dose PPI therapy; non-responders were termed EoE. ${ }^{23-25}$ By this point, the thinking about how to treat patients with PPIs had evolved from increasing PPI dose in those patients with intense esophageal eosinophilia (pre-mid-1990s), to no PPIs if a patient presented with intense esophageal eosinophilia, to a PPI trial in anyone with esophageal eosinophilia ( $\geq 15 \mathrm{eos} / \mathrm{hpf}$ ) prior to establishing a diagnosis of EoE.

Over the next few years, accumulating data suggested that the clinical, endoscopic, histologic, immunologic, and molecular characteristics were similar in both patients who would respond to PPI (PPI-REE) and in those who would not respond to PPI (ie, EoE). Baseline expression of markers for eosinophilic inflammation (eosinophil cationic protein, ECP), genes associated with a mast cell signature (carboxypeptidase $A 3, C P A 3$ ) or those involved in $\mathrm{T}_{\mathrm{h}} 2$ associated allergic inflammation (interleukin 5, IL5 and interleukin 13,IL13) including the hallmark EoE genes for eosinophil chemotaxis (eotaxin-3; CCL26), T cell activation (thymic stromal lymphopoietin; TSLP), tissue remodeling (periostin; $P O S T N$ ) and barrier function (desmoglein; DSG1), largely overlapped in patients with PPI-REE and those with EoE, and were distinct from patients with GERD and normal controls. ${ }^{26}$ Similar to what has been seen with pharmacologic therapies used to treat EoE, including topical corticosteroids or anti IL-13 biologic drugs, PPI monotherapy reversed the $\mathrm{T}_{\mathrm{h}} 2$ signature and normalized EoE diagnostic panel expression. ${ }^{27}$ Furthermore, patients with EoE who initially responded to diet and/or topical steroid therapy were eventually found to also respond to PPI therapy, and vice versa. ${ }^{28,29}$

Taken together, the data suggest that we cannot distinguish patients with esophageal eosinophilia based upon their response to PPI alone, and that PPI-REE and EoE may be at different points along a continuum. ${ }^{26,28}$ Several consensus statements have now endorsed this position. The position paper by the European Society of Eosinophilic Esophagitis supported abandoning the term "PPI-REE" 28 as did the guidelines by the United European Gastroenterology, European 
Society of Eosinophilic Esophagitis, the European Academy of Allergy and Clinical Immunology and the European Society for Pediatric Gastroenterology Hepatology and Nutrition. ${ }^{30}$ A conference of key opinion leaders was held in Chicago in May 2017 and the proceedings were published as the AGREE conference. ${ }^{1}$ With these new guidelines, we have come full circle; the need for an 8-week PPI trial as a diagnostic criteria for EoE has been eliminated in favor of adopting PPIs as a first-line therapy option along with dietary modifications and topical corticosteroids.

\section{PPI Mechanism of Action in EoE: Acid Suppression or Anti-Inflammatory?}

The mechanism(s) through which PPIs function to reduce eosinophilia in EoE have been the subject of considerable debate and research effort. ${ }^{1,31}$ The proposed mechanisms include PPI induced gastric acid-suppression leading to a restoration of esophageal barrier function, ${ }^{32}$ and PPI mediated anti-inflammatory effects unrelated to gastric acid suppression (Figure 3). ${ }^{33-37}$

\section{Epithelial Barrier Dysfunction from Gastric Acid and Reversal with PPI Therapy}

Exposure of the esophageal epithelium to gastric contents through reflux results in impaired epithelial barrier function ${ }^{38-42}$ and may directly stimulate secretion of inflammatory chemokines. ${ }^{43,44}$ Impaired mucosal integrity presents as dilated intercellular spaces (DIS) histologically ${ }^{41,45-51}$ and is associated with increased permeability, manifested as reduced mucosal impedance ${ }^{46,52-54}$ and increased paracellular flux of molecules as large as $40 \mathrm{kDa} .{ }^{55,56} \mathrm{In}$ fact, food and aeroantigens have been detected in biopsy samples from patients with active EoE. ${ }^{57,58}$ DIS and impaired mucosal integrity are characteristic features present in tissue biopsies from both GERD and EoE patients. ${ }^{59,60}$ PPIs are effective at suppressing gastric acid secretion and can help restore mucosal integrity in patients with GERD or EoE by reversing DIS and returning mucosal permeability to normal levels. ${ }^{61}$

Abundance, localization, and expression of intercellular adhesion proteins in esophageal tissue biopsies from patients with GERD and EoE are dysregulated relative to normal controls and this dysregulation can be partially recapitulated in normal esophageal biopsies by exposure to acid and bile salts. ${ }^{62}$ Epithelial barrier function of the esophagus depends on three types of adhesion complexes that bridge the intercellular space, tight junctions, adherens junctions, and desmosomes. ${ }^{63}$ Tight junctions contain occludin, and claudins 1, 4, and 7. ${ }^{64-66}$ Adherens junctions contain e-cadherin, ${ }^{67}$ and desmosomes contain desmogleins and desmocollin. ${ }^{68}$ Expression of desmoglein-1 and filaggrin are reduced in biopsy samples from patients with EoE. ${ }^{60,69}$ Exposure of esophageal mucosa to gastric contents results in increased proteolytic processing of e-cadherin. ${ }^{70}$ Furthermore, expression profiling and genetic association studies in patients with EoE have identified several epithelial barrier function genes that are either genetically associated with EoE or dysregulated in EoE including, FLG (filaggrin), DSG1 (desmoglein), KRT6B (keratin 6B), CAPN14 (calpain-14), SPINK5\&7 (SPINK5 and SPINK7). Carriage of these variants may increase sensitivity to acid and/or epithelial permeability to antigens ${ }^{6,71}$ and support a model for EoE inception that is dependent on breach of mucosal integrity by gastric acid followed by ingress of antigens and immune activation. ${ }^{32}$ PPI therapy is also able to partially restore expression of intercellular adhesion proteins and filaggrin to normal levels in patients with EoE. ${ }^{69}$

Clinically, the role of esophageal exposure to gastric acid remains controversial and has conflicting data both for and against a role of gastric acid in esophageal injury and development of EoE. ${ }^{1}$ A prospective multicenter study conducted by Frazzoni et al found that while esophageal acid exposure time (AET) was not significantly higher in patients with EoE compared to matched patients who were healthy, reflux burden as measured by the total number of reflux episodes was significantly higher, and chemical clearance as measured by the post-reflux swallow induced peristaltic wave (PSPW) index was significantly impaired. ${ }^{72}$ This suggests that there may be a degree of esophageal exposure to gastric acid that does not meet threshold criteria for GERD. Yet, data are conflicting as to whether there is a link between $\mathrm{pH}$ impedance probe data and EoE presentation, and the preponderance of studies show a lack of correlation. ${ }^{1}$ Therefore, many researchers have hypothesized an alternative, anti-inflammatory mechanism for the effects of PPI medications in EoE. ${ }^{1}$ 

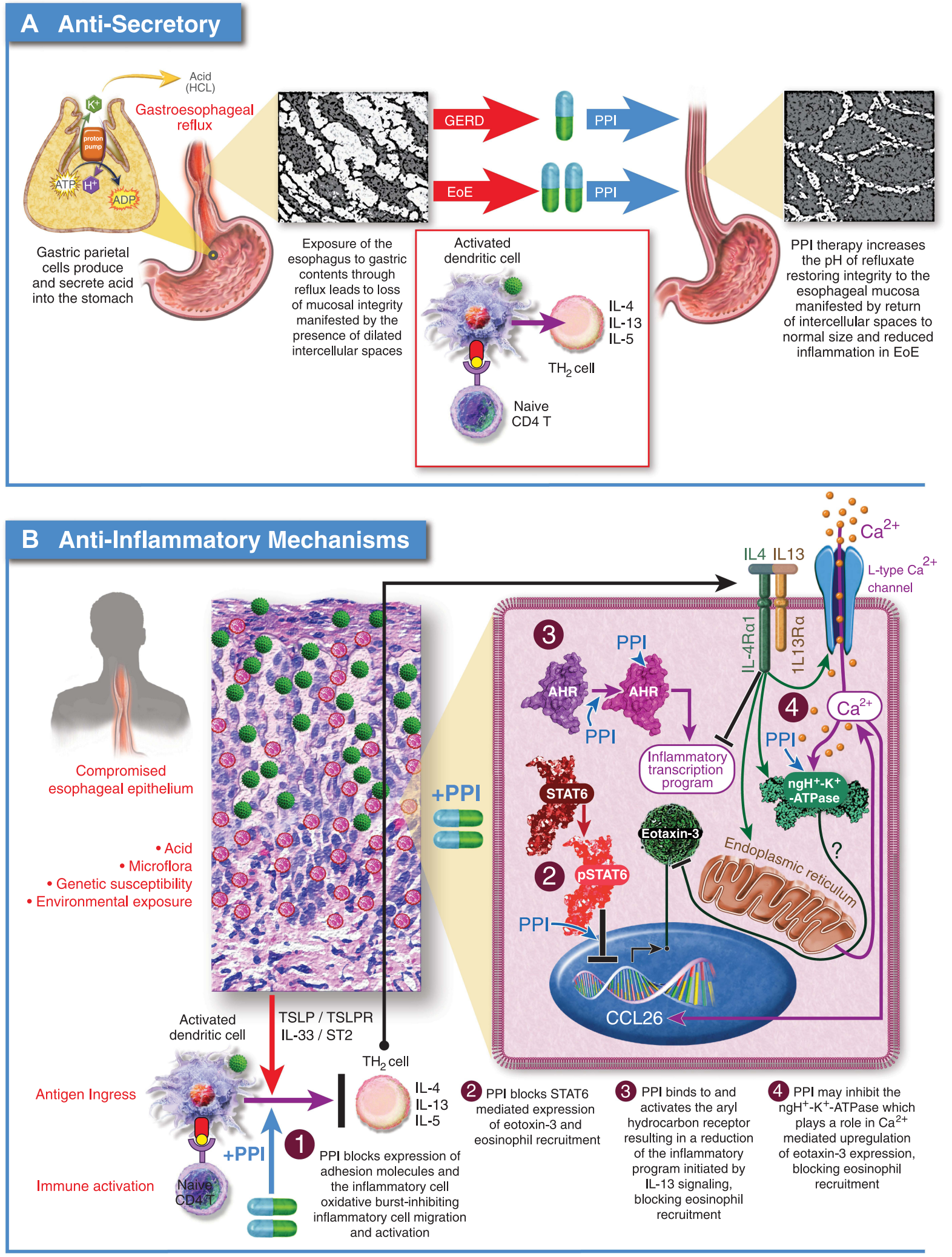

Figure 3 Proposed mechanisms of PPl efficacy for EoE. (A) Anti-Secretory Mechanism: Hypothesizes that the integrity of the esophageal epithelium is compromised by exposure to gastric acid leading to ingress of antigens and activation of an immune response. Acid suppression by PPIs allows the esophageal epithelium to heal facilitating resolution of inflammation. (B) Anti-Inflammatory Mechanisms: I.) PPls block expression of cell surface adhesion molecules, inhibiting migration of inflammatory cells to the esophageal epithelium; 2.) PPIs block STAT6 mediated expression of eotaxin-3 reducing recruitment of eosinophils to the esophageal epithelium; 3.) PPIs can stimulate the aryl hydrocarbon receptor normalizing expression of genes involved in barrier function including, filaggrin, loricrin, and involucrin through inhibition of the IL-4/IL-I3-STAT6 pathway; 4.) PPIs can inhibit the activity of ATPI2A, the non-gastric P2-type $\mathrm{H}^{+}, \mathrm{K}^{+}$-ATPase. IL-4 mediated induction of eotaxin-3 secretion is sensitive to inhibition of ATPI2A. 


\section{Anti-Inflammatory Mechanism of PPI Therapy}

There have been several proposed mechanisms for PPI therapy to reduce esophageal inflammation that include but are not limited to inhibition of eosinophil migration to the esophagus, ${ }^{33}$ inhibition of $A T P 12 A,{ }^{34}$ activation of the aryl hydrocarbon receptor ${ }^{35}$ and reduction of STAT6 mediated eotaxin-3 expression. ${ }^{36,37}$

There is emerging data to suggest that PPIs can block both the chemotactic signals and machinery required for eosinophil migration to the esophageal epithelium in EoE. Upon injury, esophageal epithelial cells of the basal layer release endogenous molecules known as alarmins (IL-25, IL-33, and TSLP). ${ }^{6,73}$ Receptors on near-by epithelial cells and tissue resident inflammatory cells sense the release of alarmins and respond by activation of the NF- $\mathrm{kB}$ signaling pathway, resulting in release of pro-inflammatory factors including cytokines VEGF, IL- $1 \alpha$, IL1 $\beta$, and TNF- $\alpha$, and chemokines IL-8, MIP-1 $\alpha$, and RANTES. ${ }^{74}$ Several of these factors including IL- $8,{ }^{75}$ MIP- $1 \alpha,{ }^{76}$ and RANTES, ${ }^{76}$ possess chemotactic properties for eosinophils. Subsequent activation of endothelial cells by these factors leads to an increase in vascular permeability (edema) and neovascularization, ${ }^{77}$ which together with their chemotactic properties, facilitate transendothelial migration of eosinophils from circulation to the epithelium. Neovascularization of the esophageal mucosa is a hallmark of EoE, the magnitude of which is directly proportional to tissue eosinophilia. ${ }^{78}$ In other work, PPIs have been shown to inhibit the expression of intercellular adhesion molecule-1 (ICAM-1) and vascular cell adhesion molecule-1 (VCAM-1) in endothelial cells at clinically relevant concentrations. ${ }^{33}$ These molecules are important for eosinophil adhesion and transendothelial migration in EoE. ${ }^{79}$

The antisecretory properties of proton pump inhibitors come from their ability to covalently inactivate ATP4A, the P-type $\mathrm{H}^{+}, \mathrm{K}^{+}$-ATPase expressed in gastric parietal cells, yet evidence suggests that PPIs can also inhibit ATP12A, the non-gastric P2-type $\mathrm{H}^{+}, \mathrm{K}^{+}$-ATPase. ${ }^{80}$ Inhibition of ATP12A by PPIs may contribute to therapeutic efficacy of PPIs in EoE. ATP12A is expressed in esophageal epithelium, and is upregulated in patients with active EoE. ${ }^{34,81}$ Using air-liquid interface (ALI) cultures of primary or telomerase immortalized human esophageal epithelial cells, Odiase et al have shown that IL-4 mediated induction of eotaxin-3 secretion is sensitive to L-type $\mathrm{Ca}^{2+}$ channel blockers verapamil and nifedipine, and to P-type $\mathrm{H}+, \mathrm{K}+$-ATPase inhibitors omeprazole and P-CAB SCH 28080. Together, these data suggest that $\mathrm{Ca}^{2+}$ signaling plays a role in cytokine mediated induction of eotaxin-3 secretion and that ATP12A may be an essential factor in this pathway. ${ }^{34}$

It has been hypothesized that activation of the aryl hydrocarbon receptor (AHR) in esophageal epithelium could reduce inflammation in EoE patients. The AHR is a member of the basic helix-loop-helix (bHLH)/Period-ARNT-Single minded (PAS) superfamily of transcription factors ${ }^{82}$ and functions as an environmental sensor, responding to both endogenous and exogenous ligands. ${ }^{83-86}$ Therapeutic activation of AHR in human models of atopic dermatitis (AD) results in reduction of histopathological and molecular hallmarks of $\mathrm{AD}$ by normalizing expression of genes involved in skin barrier function including, filaggrin, loricrin, and involucrin through inhibition of the IL-4/IL-13-STAT6 pathway. ${ }^{87-91}$ AHR is expressed in most human tissues including esophageal mucosa. ${ }^{81}$ In the GI tract, AHR activation by microbial and dietary agonists upregulates expression of antimicrobial peptides, shifts intraepithelial lymphocyte polarization to an anti-inflammatory, tissue-protective phenotype, and preserves intestinal barrier integrity. ${ }^{92,93}$ Proton pump inhibitors have long been known to activate AHR at concentrations that are therapeutic. ${ }^{94-96}$ Recently, Rochman et al characterized the transcriptional response of human esophageal epithelial cells following exposure to omeprazole or esomeprazole using submerged cultures. Of the 479 genes induced by PPI exposure, approximately 200 of them were regulated by AHR. Of note, omeprazole or esomeprazole treatment reduced the level of IL-13 stimulated secretion of eotaxin-3 by telomerase immortalized and primary esophageal epithelial cells about 2-fold; an effect that was shown to be dependent on AHR. ${ }^{35}$

Esophageal eosinophilia in EoE is driven largely by STAT6-dependent local expression of eotaxin-3 ${ }^{97,98}$ Zhang et al and Cheng et al, using similar culture models, showed that omeprazole at therapeutic levels blocked IL-4/IL-13 stimulated increases in eotaxin-3 messenger RNA expression and protein secretion by inhibiting the chromatin remodeling necessary for STAT6 binding to the eotaxin-3 promoter. ${ }^{36,37}$ Additional data from Park et al ${ }^{99}$ and Min et al ${ }^{80}$ suggest that PPI treatment has a similar effect on eotaxin-3 expression in the proximal esophagus of pediatric EoE patients and in nasal polyp tissue from patients with chronic rhinosinusitis. These data are also consistent with work showing that EoE patients who carry genetic variants in STAT6 that associate with increased levels of inflammation respond poorly to PPI 
therapy for both induction and maintenance phase therapies. ${ }^{2,3}$ Together, these data suggest that reduction of STAT6 mediated expression of eoxtain-3 is an important mechanism through which PPIs function to reduce esophageal eosinophilic inflammation in EoE.

\section{Effect of PPI Therapy on Esophageal Mast Cell Infiltration in EoE}

While diagnostic criteria and response to therapy in EoE focus on eosinophilic infiltration, numerous studies have demonstrated the contribution of mast cells to both expression of esophageal symptoms and endoscopic abnormalities, despite histological normalization of eosinophil counts. Little is known regarding how mast cells respond to PPI when used for treatment of EoE. A study by Iwakura et al demonstrated no difference in pretreatment esophageal mast cell counts in PPI responsive vs PPI non-responsive EoE patients. ${ }^{100}$ Bolton et al recently found that even when controlling for treatment modality (PPI vs corticosteroids vs dietary), mast cell density was associated with increased symptoms, endoscopic findings, and epithelial abnormalities, despite resolution of esophageal eosinophilia. ${ }^{101}$ Kanagaratham et al showed that omeprazole blocked mast cell degranulation and the release of preformed proinflammatory cytokines (including IL-4, IL-13, and TNF- $\alpha$ ) from cultured presensitized human cord blood mast cells. This may result from reduced phosphorylation of key signaling molecules of the antigen, IgE, FceRI signaling cascade (SYK, ERK) and decreased cytosolic $\mathrm{Ca}^{2+}$, which is essential for inflammatory granule exocytosis. Omeprazole was also found to block mast cell maturation, dampen passive IgE-mediated anaphylaxis, and attenuate mast cell-dependent allergic inflammation in a murine model of food allergy. ${ }^{102}$ Whether mast cell predominant EoE patients represent a significant fraction of PPI non-responders is not known. Given that EoE is a multifactorial disease with potentially many pathways resulting in allergic inflammation of the esophagus, it remains a possibility that mast cells are a significant driver of pathophysiology in EoE.

\section{PPI Efficacy for Esophageal Eosinophilia and EoE in Adults}

Many studies over the past 15 years have examined efficacy of PPIs for treatment of EoE in adults (or, at the time of their publication, symptomatic esophageal eosinophilia in patients suspected of having EoE). The data have been reviewed extensively in the most recent AGREE EoE diagnostic guidelines, ${ }^{1}$ where they helped to form the basis for removing the so-called "PPI-trial" from the diagnostic algorithm and retiring the term "PPI-REE". In addition, there have been two meta-analyses, ${ }^{103}$ the most recent being the technical review that supported the 2020 American Gastroenterology Association/Joint Task Force (AGA/JTF) EoE management guidelines. The individual studies include randomized trials comparing a PPI to a topical steroid, ${ }^{104,105}$ prospective cohorts, ${ }^{22,55,98,106-113}$ and retrospective cohorts; ${ }^{114-124}$ there are no placebo-controlled trials of PPIs in EoE, and relatively fewer studies in the timeframe after the AGREE guidelines and the "retirement" of the term PPI-REE. ${ }^{125-127}$ Most studies report both histologic response rates (though the thresholds defining response can vary) ${ }^{128}$ and overall symptom response rates, though few if any use validated symptom metrics. Of note, the PPI doses and specific medications vary between studies, as do the treatment time courses. The literature on PPI efficacy in adults with EoE is therefore heterogeneous but remains consistent in supporting the utility of this treatment modality (Figure 4).

In the first randomized trial conducted in this area, Peterson et al compared esomeprazole $40 \mathrm{mg}$ daily to swallowed fluticasone $440 \mathrm{mcg}$ twice daily for an 8-week course in adults with $\mathrm{EoE}\left(\mathrm{n}=15\right.$ in each group). ${ }^{104}$ For the 12 and 13 patients who completed the PPI and steroid treatments, respectively, the histologic response rates ( $<15$ eos/hpf threshold $)$ were $50 \%$ for esomeprazole and $31 \%$ for fluticasone $(\mathrm{p}=0.28)$. Symptom responses (defined as a decrease in an 8 -point dysphagia score by at least 2 points) were $25 \%$ with PPI and $50 \%$ with steroid $(\mathrm{p}=0.40)$. The other randomized study, by Moawad et al, also compared esomeprazole $40 \mathrm{mg}$ daily and swallowed fluticasone $440 \mathrm{mcg}$ twice daily for an 8 -week course. ${ }^{105}$ In the 42 patients randomized, histologic response $(<7 \mathrm{eos} / \mathrm{hpf})$ was seen in $33 \%$ with PPI and $19 \%$ with corticosteroids $(\mathrm{p}=0.48)$, and symptoms (as measured by the Mayo Dysphagia Questionnaire) ${ }^{129}$ improved more with the PPI.

These response rates are in line with what has been noted in multiple other studies on this topic. The study that garnered the most initial attention related to PPI response in adults with EoE was by Molina-Infante et al. ${ }^{22}$ In this prospective cohort of 35 patients with esophageal eosinophilia $\geq 15$ eos $/ \mathrm{hpf}, 75 \%$ had a histologic response $(<5$ eos $/ \mathrm{hpf})$ 


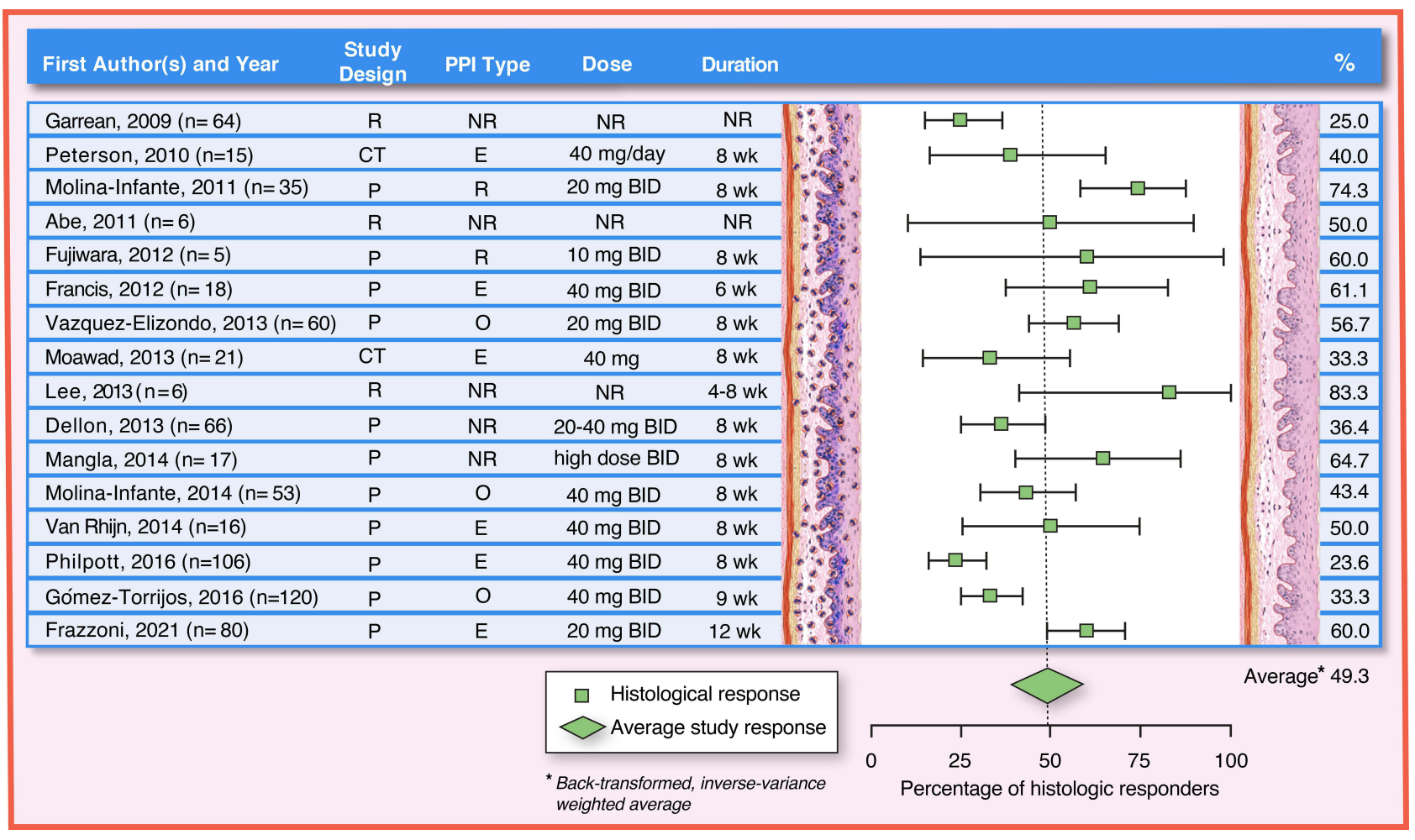

Figure 4 PPI efficacy in adults: histologic remission $\left(<15\right.$ eos/hpf). The analysis was conducted using the R statistical package metafor, ${ }^{210}$ assuming a fixed effects model and using inverse-variance weighting. The reported summary statistic is the back-transformed inverse-variance weighted average for histologic remission across all studies listed in adults. References: Garrean, 2009, ${ }^{211}$ Peterson, 2010, ${ }^{104}$ Molina-Infante, 20II, ${ }^{22}$ Abe, 201I, ${ }^{19}$ Fujiwara, $2012,{ }^{108}$ Francis, $2012,{ }^{109}$ Vazquez-Elizondo, 20I3, ${ }^{110}$ Moawad, 2013, ${ }^{105}$ Lee, 2013, ${ }^{122}$ Dellon, 2013, ${ }^{107}$ Mangla, 2014, ${ }^{212}$ Molina-Infante, 2014, ${ }^{98}$ Van Rhijn, 2014, ${ }^{55}$ Philpott, $2016,{ }^{113}$ Gómez-Torrijos, $2016,{ }^{1 / 2}$ Frazzoni, 202I ${ }^{125}$. Abbreviations: Study Design: CT, clinical trial; P, prospective study design; R, retrospective study design; PPI Type: E, esomeprazole; NR, not reported or any available; O, omeprazole; R, rabeprazole; Dose: BID, two times a day; mg, milligram; NR, not reported; Duration: NR, not reported; wk, week.

to rabeprazole $20 \mathrm{mg}$ twice daily. On additional analyses, there were 21 patients who did not have endoscopic evidence of acid damage, and of these, $14(67 \%)$ had a PPI response. Symptom response (as measured on a multi-symptom questionnaire) was seen in a similar proportion. In another prospective cohort of 173 patients with dysphagia, 66 (38\%) had esophageal eosinophilia $\geq 15$ eos/hpf, 24 of whom (36\%) responded to twice daily PPI treatment with a variety of the approved medications. ${ }^{107}$ More recently, Laserna-Mendieta et al reported on real-world practices in the EOS Connect Registry, and found that in over 600 patients examined, the histologic response rate $(<15$ eos/hpf) was $49 \%$ and symptom response (at least a 50\% decrease in a symptom score) was 71\%. ${ }^{130}$ In another recent study, Franzzoni et al found a histologic response rate $(<15 \mathrm{eos} / \mathrm{hpf})$ of $60 \%$, with associated improvement in dysphagia symptom scores. ${ }^{125}$

At the time of the AGREE consensus paper, the range of PPI histologic responses from all prospective and retrospective studies conducted in adolescents and/or adults ranged from $23 \%$ to $74 \%$. Response ranges were similar regardless of study design, and symptom response tended to be similar or better. In the meta-analysis by Lucendo et al, the histologic response rate for PPI treatment in adults was 49.6\% (95\% CI: 40.1-59.2) while clinical response rate was $60.8 \%$ (95\% CI: 48.4-72.2), though heterogeneity was high $\left(\mathrm{I}^{2}=80.2\right) .{ }^{103}$ These data were corroborated in the recent technical review by Rank et al, which showed a pooled histologic response rate of 47.4\% (95\% CI: 39.9-55.0), though this analysis was not stratified by patient age. ${ }^{131}$ Based on this, the AGA/JTF EoE management guidelines recommended PPI therapy for patients with symptomatic esophageal eosinophilia (but this is a conditional recommendation with very low-quality evidence). ${ }^{7}$ Of note, these guidelines raised several caveats regarding data quality including lack of placebocontrolled studies, multiple retrospective studies, and heterogeneity in study design (patient selection, PPI doses, PPI type, and duration of treatment). Given these limitations, AGA/JTF EoE management guidelines fell short of making therapeutic recommendations regarding PPI use to treat EoE in adults. Current expert opinion suggests that adequate PPI therapy for EoE parallels therapeutic recommendations for GERD and involves 20-40 mg, once or twice daily for 8 to 12 
weeks (induction phase) depending on the patient and chosen PPI, ${ }^{23,24}$ followed by an additional EGD with biopsy to assess disease activity. ${ }^{7}$ While the relevant criteria to establish endoscopic and histologic improvement are currently under active investigation, a threshold of $<15$ eos/hpf to define an adequate therapeutic response has been used by a majority of investigators ${ }^{128}$ and is complementary to the established threshold of $\geq 15$ eos/hpf for active disease. ${ }^{8}$ The $\mathrm{AGA} / \mathrm{JTF}$ authors concluded that $<15 \mathrm{eos} / \mathrm{hpf}$ is reasonable threshold until a more robust, evidence-based measure is established. ${ }^{7,132,133}$

Once a PPI response has been achieved, there are some limited data informing long-term outcomes. In a multi-center study by Molina-Infante et al, of 75 adults responsive to PPI treatment over a mean follow-up time of 26 months, $73 \%$ maintained remission after decreasing the PPI dose, and another 14\% regained response with a dose increase. ${ }^{134}$ Thus, $13 \%$ had lost response in 1-2 years. In the EOS Connect Registry, ongoing clinico-histologic remission was seen in $69 \%$ of subjects treated for at least 6 months. ${ }^{130}$ In recent data presented in abstract form, Thakkar et al reported histologic and clinical response rates for PPI therapy of $60 \%$ and $64 \%$, respectively, in population with a mean follow-up time of $3.6 \pm$ 2.9 years. $^{135}$

In summary, PPI therapy in EoE is an important treatment for adults with symptomatic esophageal eosinophilia and EoE, and histologic response can be seen in up to $50 \%$ of patients, with likely more having symptom response. PPIs are now positioned as a first-line pharmacologic option for EoE, rather than as a diagnostic criterion.

\section{PPI Adverse Events in Adults with EoE}

PPI medications were first available in the 1980s and are among the most commonly prescribed medications in adults for upper GI tract disorders with 91.8 million prescriptions written in 2019 in the $\mathrm{US}^{136}$ alone and a global market estimated to be valued at US \$2.9 billion in 2020, which is expected to exhibit a compound annual growth rate of 4.30\% through 2027. ${ }^{137}$ Yet despite PPIs' popularity, their safety profile is controversial. ${ }^{138,139}$ As PPI therapy in EoE may potentially be long-term and high dose, consideration of adverse events is important for prescribers and patients. The AGREE consensus guidelines including the referenced articles did not address adverse events. The recent AGA/JTF EoE management guidelines did not make specific recommendations with regard to long-term monitoring but do acknowledge that there are multiple unresolved issues including establishing the optimal minimal duration of PPI treatment before repeat endoscopy, the optimal dose and duration of PPI use as a primary EoE treatment, the optimal duration of long-term PPI treatment if a PPI response is observed, and determining the next best treatment if inflammation persists despite PPI therapy. ${ }^{7}$ Adverse events associated with PPI therapy for EoE are likely to be the same as adverse events for other indications, however the higher dosage currently recommended for treating EoE patients may lead to increased prevalence and severity of side effects as many side effects associated with PPI use are known to be dose dependent. ${ }^{140}$ Although a comprehensive review of general PPI adverse events is beyond the scope of this article, it is important to note that the Food and Drug Administration (FDA) has specifically cautioned PPI standard dose users on the risks for Clostridioides (formerly clostridium) difficile infection, ${ }^{141}$ bone fractures ${ }^{142}$ and hypomagnesemia. ${ }^{143}$ There have been numerous meta-analyses for standard dose PPI therapy citing both associations and lack of association of PPI use and pneumonia, ${ }^{14-148}$ other enteric infections, ${ }^{149-151}$ gastric atrophy and cancer, ${ }^{152-154}$ chronic kidney disease, ${ }^{155-159}$ diabetes, ${ }^{160,161}$ chronic obstructive lung disease, ${ }^{162,163}$ dementia, ${ }^{164-169}$ cardiovascular disease or cardiovascular events, ${ }^{170-175}$ and all-cause mortality. ${ }^{176-180}$ However, it is likely that most of the reported potential risks are due to residual confounding within the study design, ${ }^{180-183}$ and a large-scale, industry sponsored randomized controlled trial recently emphasized the safety of this medication class and refuted most of the prior proposed associations. ${ }^{176}$ FDA PPI package labeling does not address high dose twice daily therapy for EoE (not an FDA approved indication), and the lowest dose and shortest duration of PPI therapy are general prescribing recommendations. Along these lines, Molina-Infante et al observed a $73 \%$ sustained histological remission rate following $>1$ year on low-dose (once a day) PPI maintenance therapy in a retrospective cohort of 75 patients who were initially responsive to 8-weeks of high dose PPI therapy. Adverse events while on maintenance therapy were not discussed although it was noted that none of the 75 patients discontinued PPI treatment during the follow-up period. ${ }^{134}$ The long-term risk of high dose and potentially lifelong PPI therapy remain an area that requires investigation in EoE, but based on experience in GERD and Barrett's esophagus, the risk-benefit profile is likely favorable. Precision medication for PPI therapy has the potential to optimize PPI efficacy and minimize toxicity and has been 
recommended from the recent Clinical Pharmacogenetics Implementation Consortium (CPIC) guidelines by Lima et al for $H$. pylori and Erosive Esophagitis and will be discussed below as a future consideration for EoE therapy. ${ }^{184}$

\section{PPI Efficacy in Children}

As summarized in the most recent AGREE EoE guidelines, ${ }^{1}$ the published studies on efficacy of PPI in EoE in children have many differences in the doses and duration of PPI. Because of that, the heterogeneity in the results is high between publications, with the histologic response rates ranging from $23 \%$ to $83 \%$, and clinical response rates ranging from $23 \%$ to $82 \%$ in children. ${ }^{1}$ In the last two decades, several studies evaluating the efficacy of PPI in children with EoE have been published. ${ }^{19-21,185-187}$ Most studies report histologic response rates (with different thresholds, variable PPI doses and treatment durations) with less data on symptomatic response, and none of the studies use validated symptom scores (Figure 5).

There are scarce data that compare PPIs as the primary treatment for children with dietary elimination or topical corticosteroids, as the previous definition of EoE included the non-response to a PPI trial. In 2006, Ngo et al published a case series of two children and one adult with a clinical history of dysphagia, food impaction and vomiting, furrows, and exudates in the endoscopy and $>20$ eos/hpf in the esophageal mucosa. ${ }^{19}$ After PPI monotherapy (dose between 1 and 2 $\mathrm{mg} / \mathrm{kg} /$ day), symptoms improved, the endoscopic findings returned to normal and the eosinophilic infiltration of the esophagus resolved. ${ }^{19}$ In a retrospective study published by Sayej et al in 2009, 14 of 36 (39\%) patients with esophageal eosinophilia responded histologically $(<15$ eos/hpf) to a three-month course of omeprazole, esomeprazole or lansoprazole 1-2 mg/kg/day, divided twice daily. ${ }^{21}$ In another retrospective study, Dranove et al treated 43 children with esophageal eosinophilia with PPI at an average dose of $1 \mathrm{mg} / \mathrm{kg}$ /day for an unknown duration, with a $40 \%$ rate of histologic response $\left(<5\right.$ eos/hpf). ${ }^{20}$ The histologic response rate was not associated with the results of $\mathrm{pH}$ probe testing; $41 \%$ of children with an abnormal $\mathrm{pH}$ probe test responded vs $45 \%$ of children with normal $\mathrm{pH}$ probe test. In 2013, Schroeder et al conducted a retrospective study in 35 children with esophageal eosinophilia treated at least 3 months with PPI at a dose of $1-2 \mathrm{mg} / \mathrm{kg} /$ day and observed a $22.8 \%$ histologic response rate $(<15 \mathrm{eos} / \mathrm{hpf}) .{ }^{185} \mathrm{In}$ a prospective study in 2013 , Rea et al included 25 patients with esophageal eosinophilia $>15 \mathrm{eos} / \mathrm{hpf}$ treated with repeated cycles of PPI (type, dose and duration not specified), observing histologic response (threshold not defined) in $15(60 \%) .{ }^{186}$ Histologic response was observed in $4 / 9$

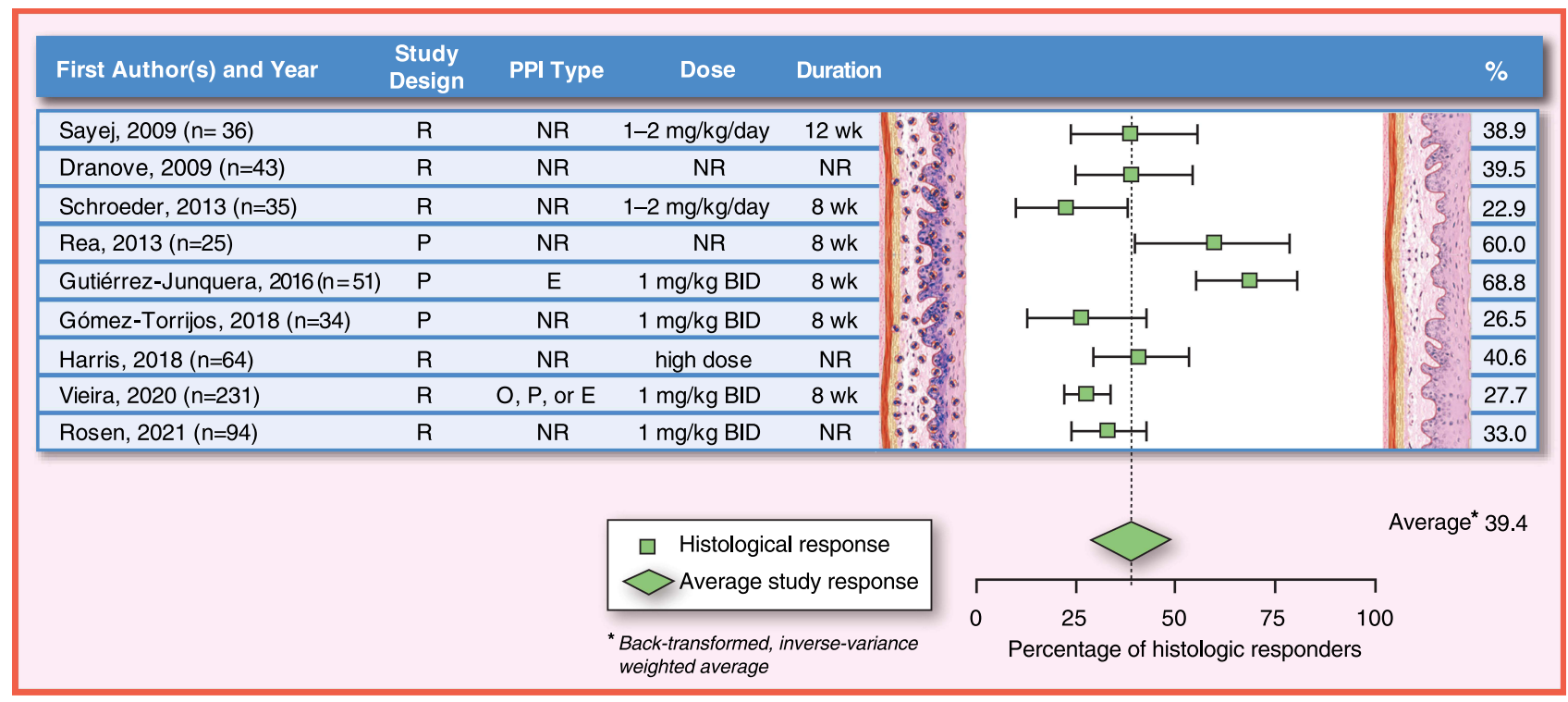

Figure 5 PPI efficacy in children: histologic remission $\left(<15\right.$ eos/hpf). The analysis was conducted using the $R$ statistical package metafor, ${ }^{210}$ assuming a fixed effects model and using inverse-variance weighting. The reported summary statistic is the back-transformed inverse-variance weighted average for histologic remission across all studies listed in children. References: Sayej, 2009, ${ }^{21}$ Dranove, 2009, ${ }^{20}$ Schroeder, 2013, ${ }^{185}$ Rea, 2013, Gutiérrez-Junquera, 2016, ${ }^{187}$ Gómez-Torrijos, $2018,{ }^{188}$ Harris, 2018, ${ }^{213}$ Vieira, $2020,{ }^{189}$ Rosen, $2021^{214}$.

Abbreviations: Study Design: P, prospective study design; R, retrospective study design; PPI Type: E, esomeprazole; NR, not reported or any available; O, omeprazole; P, pantoprazole; Dose: BID, two times a day; kg, kilogram; mg, milligram; NR, not reported; Duration: NR, not reported; wk, week. 
(44\%) patients with normal $\mathrm{pH}$ Multichannel Intraluminal Impedance (pH-MII) test results and in 11/16 (69\%) of those with abnormal pH-MII test results. In the latter group, 4 patients underwent fundoplication due to PPI dependence, allowing discontinuation of PPI without histological recurrence, indicating that the response may be due to gastroesophageal reflux. The results of previous studies, mostly retrospective and only one prospective, were analyzed by Lucendo et al in a systematic review with a meta-analysis, published in 2016, which included 188 children, the pooled histologic response in children was $54 \%(95 \% \mathrm{CI}, 38-70)$, although heterogeneity was high $\left(\mathrm{I}^{2}=66 \%\right)$. The clinical response was higher $65 \%(95 \%, \mathrm{CI}, 43-84)$, but with even higher heterogeneity $\left(\mathrm{I}^{2}=84 \%\right) .{ }^{103}$

In 2016, Gutiérrez-Junquera et al conducted a prospective study of 51 children with esophageal eosinophilia who received $2 \mathrm{mg} / \mathrm{kg}$ /day of esomeprazole, divided twice daily for 8 weeks. They reported that $35(68.6 \%)$ of the patients had a histological response $\left(<15\right.$ eos/hpf) and 24 (47\%) achieved eosinophilic infiltration $<5$ eos/hpf. ${ }^{187} \mathrm{~A}$ pH-probe test was performed on 31 of the 51 children. No difference in any of the pH-probe test parameters was found between responders and non-responders to PPI, with only one non-responder patient showing abnormal acid reflux. Almost $80 \%$ of the children had clinical improvement with PPI treatment regardless of response of eosinophilic infiltration. In most published studies, the rate of clinical response to PPI treatment was also higher than the rate of histological response. ${ }^{20,21}$

More recently, in a prospective study by Gómez-Torrijos et al, 9 of 34 (26.5\%) children achieved histologic response $\left(<15\right.$ eos/hpf) after 2 months of treatment with omeprazole $2 \mathrm{mg} / \mathrm{kg} /$ day, divided twice daily. ${ }^{188} \mathrm{In}$ a retrospective study by Vieira et al, 64 of 231 (27.7\%) children with esophageal eosinophilia responded histologically ( $<15$ eos/hpf) to a 2 months course of PPI (omeprazole, pantoprazole, or esomeprazole) at a dose of $2 \mathrm{mg} / \mathrm{kg} /$ day, divided twice daily. ${ }^{189}$

For long-term PPI maintenance therapy, initial data suggested that PPI response in children with esophageal eosinophilia was a transient phenomenon, with description of some cases that recurred while receiving PPI treatment. ${ }^{185,190}$ However, in 2018, Gutiérrez-Junquera et al published a prospective study of 57 children with EoE and histological response to an 8 -week esomeprazole trial $(2 \mathrm{mg} / \mathrm{kg} /$ day, divided twice daily) followed by esomeprazole at $1 \mathrm{mg} / \mathrm{kg} / \mathrm{day}$ for 1 year. Forty-nine children (86\%) remained asymptomatic and histological response on maintenance PPI therapy was present in 40 children (70.1\%). ${ }^{191}$ Long-term response rate was higher in children with initial complete histological response $(\leq 5$ eos/ hpf) than in those with partial response (6 to 14 eos/hpf) (81\% vs 50\%). Eleven out of 12 children (91.6\%) receiving esomeprazole $0.5 \mathrm{mg} / \mathrm{kg} / \mathrm{day}$ for 12 additional months remained in remission.

Overall, based on limited literature, PPIs appear to be effective in the short- and long-term treatment of EoE in children. However, the degree of response achieved is highly variable between different clinical centers. Based on available evidence, the recommended induction dose is $1-2 \mathrm{mg} / \mathrm{kg} /$ day, divided twice daily, with a maximum of $40 \mathrm{mg}$ twice a day for esomeprazole and omeprazole and $30 \mathrm{mg}$ twice a day for lansoprazole for 8 to 12 weeks with a follow-up endoscopic and histological examination. The optimal dose and duration for maintenance treatment as well as endoscopic surveillance frequency are unresolved issues that warrant further investigation. Most experts agree that stepping down PPI therapy to the lowest dose possible that maintains remission is recommended. Large scale, prospective long-term follow-up studies for PPI therapy for pediatric EoE with validated outcomes are needed that address not only efficacy but also safety in children for induction of remission and as maintenance therapy.

\section{PPI Adverse Events in Children with EoE}

Proton pump inhibitors are the most commonly prescribed drugs for pediatric upper gastrointestinal tract disorders, and PPI prescription rates continue to rise with emerging and controversial safety concerns. ${ }^{192-195}$ Consideration must be given to potential PPI-associated adverse events in children with EoE, as per $\mathrm{kg}$ dosing in children $(1 \mathrm{mg} / \mathrm{kg} / \mathrm{day}$, divided twice daily up to adult maximum dose) is often significantly higher than adults ( $40 \mathrm{mg}$ twice daily) and therapy duration could extend through childhood and well into adulthood. The timing of PPI therapy initiation must also be considered as infants treated with PPI may have increased risk of subsequently developing EoE. ${ }^{196,197}$ In a recent prospective pediatric study, Torrijos et al reported an $8.3 \%$ risk of adverse events among 34 patients adherent to therapy, and a $15 \%$ rate of non-adherence to high dose PPI therapy for children with EoE. ${ }^{188}$

As the mechanism for PPI adverse events in pediatric EoE should be no different than other PPI indications, it is important to recognize the potential for associations between PPI use and comorbidities in children. ${ }^{140}$ Numerous studies of adverse events associated with PPI use have been conducted, yet the absolute risk of PPI therapy in children remains 
controversial. ${ }^{198,199}$ While many of these studies are limited by sample size and study design, safety concerns based on case-control studies in children suggest an increased risk of necrotizing enterocolitis, pneumonia, upper respiratory tract infections, sepsis, urinary tract infections, C. difficile infections, and fractures. ${ }^{199,200}$ A randomized, placebo-controlled clinical trial by the American Lung Association's Asthma Clinical Research Centers (ACRC) on the efficacy of PPI to improve asthma symptoms in 300 children with poorly controlled asthma reported increased prevalence rates of upper respiratory infection, sore throat and bronchitis in participants taking PPI compared to placebo. ${ }^{201}$ Previous studies have suggested that CYP2C19 poor PPI metabolizers may be particularly at risk for adverse events. ${ }^{184}$ Current CPIC guidelines do provide some pediatric literature, but more research is needed into PPI therapy for EoE to better characterize safety concerns. ${ }^{184}$

\section{The Future: PPI Precision Medicine for EoE}

As our knowledge of the etiology and pathophysiology of EoE improves and novel therapies emerge, a shift from conventional to precision medicine is inevitable. ${ }^{202,203}$ The potential benefits of a precision medicine approach for EoE are clear: timely initiation of optimal therapy with a reduction or elimination of empirical dosing trials and adverse events, and an overall reduction in health-care utilization and improved quality of life. A proposed precision medicine framework for PPI therapy in EoE is provided in Figure 6.

Given the recent advances made in multi-omic analytical pipelines that integrate information from phosphoproteomics, proteomics, transcriptomics, DNA methylation, microRNA profiling and genomics, the goals of precision medicine are evolving from aspirational to standard of care. Perhaps, the best example of this timely transition is in cancer medicine where a recent tour-de-force from Huang et al used a "proteogenomics" approach to identify three distinct molecular subtypes of head and neck squamous cell carcinoma with high potential for treatment with three separate and distinct therapies. ${ }^{204}$ For gastroenterology, use of pharmacogenomic testing for TPMT metabolizer genotype has become common practice when using Azathioprine or 6-Mercaptopurine in inflammatory bowel disease and autoimmune hepatitis. ${ }^{205}$ Recently, CPIC published guidelines for CYP2C19 genotype guided PPI therapy. ${ }^{184}$ Available adult and pediatric data support the use of $150-200 \%$ of standard PPI dosing for CYP2C19 extensive metabolizers for $H$ pylori therapy and erosive esophagitis.

Over the last decade, it has become increasingly clear that at the molecular level, not all EoE patients are the same. Current research is focused on identifying a minimal set of informative markers (transcriptomic, genomic, proteomic, metabolomic, etc.) that predict how a patient will respond to PPIs for EoE (ie, low-dose PPI responders, high-dose PPI responders, PPI non-responders) prior to initiation of therapy. Factors that interact with disease phenotypes such as pharmacogenetic variants that influence response to PPIs (eg, CYP2C19*17) or genetic variants that associate with PPI pharmacodynamics (eg, STAT6 rs324011), will be important considerations for implementing precision medicine strategies (Figure 6). To date, Shoda et al have published the most comprehensive attempt at identifying molecular endotypes of patients with active EoE. ${ }^{206}$ Newer studies are examining exciting ideas including identifying EoE biomarkers and phenotypes that might respond to PPI; a recent study of 630 patients with EoE from the multi-center EUREOS EoE CONNECT Registry who received PPI therapy showed that inflammatory phenotype and treatment duration of up to 12 weeks correlated with greater chance for inducing remission of EoE. ${ }^{127}$ On the other hand, a stricturing phenotype decreased response rates to PPI both at induction and in maintenance phases. ${ }^{127}$ In a separate study, Cañas et al have identified several microRNAs in esophageal biopsy tissue that may discriminate between PPI responders and non-responders at baseline. ${ }^{207}$

In addition to phenotype classifications, individual patient genetic variations have been shown to influence response to medications. A recently conducted pilot study of CYP2C19 genotype-guided PPI therapy in children with gastric acid associated conditions suggests reduced PPI-associated infections with guided-therapy. ${ }^{208}$ In EoE, we have shown that STAT6 genetic variants are associated with a 6.1-fold increased risk of failure to achieve complete remission with PPI therapy. ${ }^{3}$ 


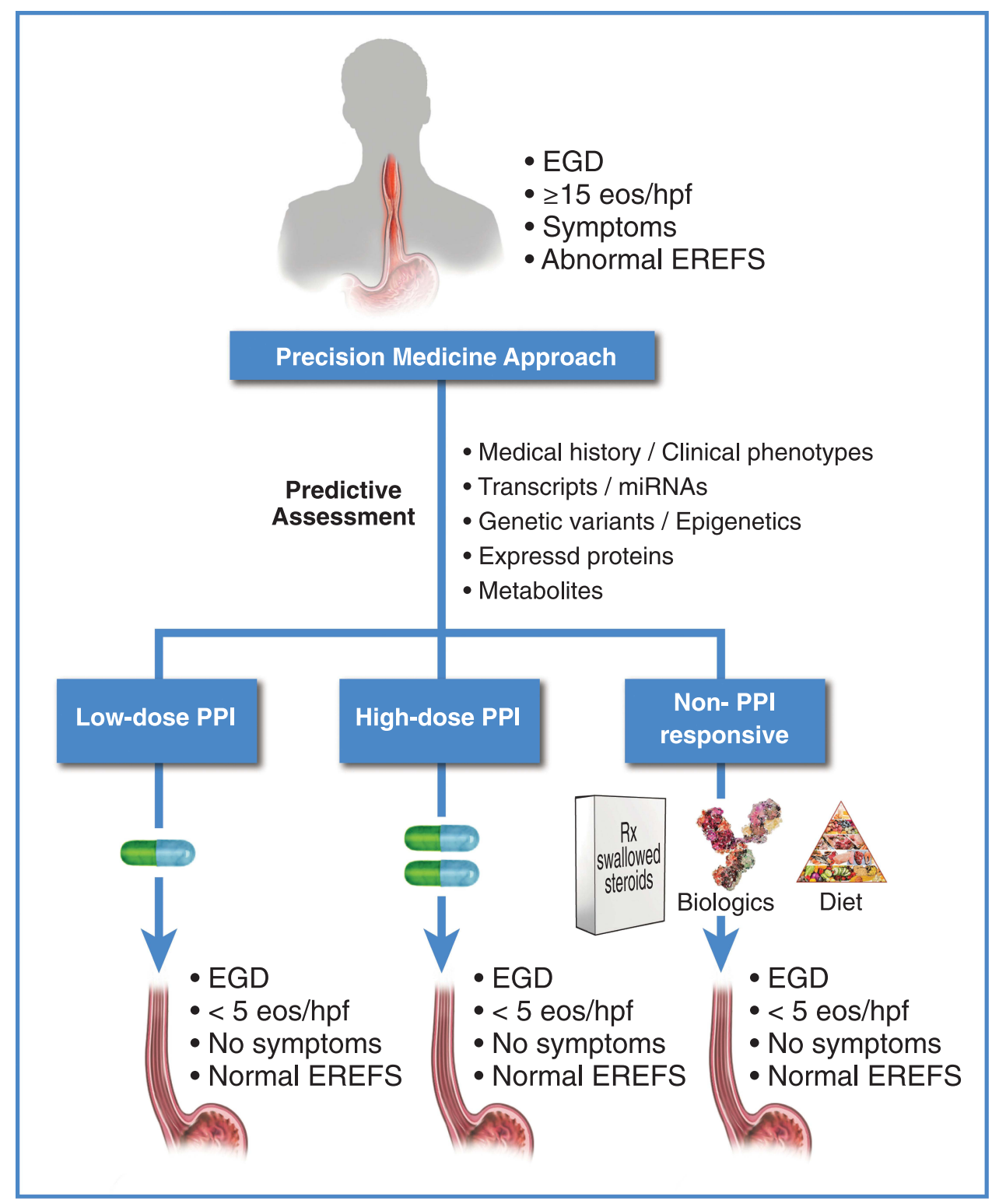

Figure 6 Therapy for eosinophilic esophagitis: framework for proposed future directions. Current research is focused on identifying a minimal set of non-invasive informative markers (transcriptomic, ${ }^{27,126,215}$ genomic, ${ }^{3}$ proteomic, ${ }^{216}$ metabolomic, history, etc.) that predict how a patient will respond to PPIs for EoE. For a review of potentially informative non-invasive biomarkers that predict active EoE, see Votto et al. ${ }^{217}$ Some of the biomarkers reviewed by Votto et al may also be informative for a PPIresponsive outcome when assessed prior to PPI therapy. Given this information, patients can potentially be identified as low-dose PPI responders, high-dose PPI responders, PPI non-responders, etc., prior to initiation of therapy, allowing selection of the appropriate therapy to achieve resolution of inflammation.

\section{Conclusions}

In conclusion, PPI therapy for esophageal eosinophilia and EoE has evolved over the past several years to now become a primary therapy for EoE in both children and adults. Efficacy data of PPI therapy for EoE in children and adults are heterogenous and variable, and there are no randomized, placebo controlled clinical trials of PPIs for EoE. Large-scale prospective safety data are also lacking, particularly for high dose twice daily PPI therapy for EoE. All therapies for EoE warrant a comprehensive, thoughtful, and balanced evaluation from health-care providers and patients. Precision medicine for PPI therapy for children and adults with EoE will enable appropriate patient and dose selection that optimizes efficacy and minimizes toxicity. Large scale, longitudinal, validated outcome studies for induction of remission and long-term maintenance with PPI precision medicine dose optimization are urgently needed. 


\section{Acknowledgments}

We would like to acknowledge Joe Chovan of Healthcare Visuals for his technical excellence in preparation of the figures that appear within the manuscript.

\section{Funding}

This work was funded by a Nemours Research Foundation grant to JPF.

\section{Disclosure}

JPF: No conflicts of interest to report. EBM: No conflicts of interest to report. ESD: Research funding: Adare/Ellodi, Allakos, Arena, AstraZeneca, GSK, Meritage, Miraca, Nutricia, Celgene/Receptos/BMS, Regeneron, Shire/Takeda. Consultant: Abbott, AbbVie, Adare/Ellodi, Aimmune, Allakos, Amgen, Arena, AstraZeneca, Avir, Biorasi, Calypso, Celgene/Receptos/BMS, Celldex, Eli Lilly, EsoCap, GSK, Gossamer Bio, Landos, Morphic, Nutricia, Parexel/Calyx, Phathom, Regeneron, Revolo, Robarts/Alimentiv, Salix, Sanofi, Shire/Takeda. Educational grant: Allakos, Banner, Holoclara. CG-J: No conflicts of interest to report. SF-F: No conflicts of interest to report. RDV: No conflicts of interest to report. SKG: Consultant Abbott, Adare/Ellodi, Allakos, Celgene, Gossamer Bio, QOL, UpToDate, Medscape, Viaskin. Research support Shire; Allakos; Adare/Ellodi; NIH U54 grant to CEGIR.

\section{References}

1. Dellon ES, Liacouras CA, Molina-Infante J, et al. Updated international consensus diagnostic criteria for eosinophilic esophagitis: proceedings of the AGREE conference. Gastroenterology. 2018;155:1022-1033 e10. doi:10.1053/j.gastro.2018.07.009

2. Mougey EB, Nguyen V, Gutierrez-Junquera C, et al. STAT6 variants associate with relapse of eosinophilic esophagitis in patients receiving long-term proton pump inhibitor therapy. Clin Gastroenterol Hepatol. 2020;19:2046-2053.e2. doi:10.1016/j.cgh.2020.08.020

3. Mougey EB, Williams A, Coyne AJK, et al. CYP2C19 and STAT6 variants influence the outcome of proton pump inhibitor therapy in pediatric eosinophilic esophagitis. J Pediatr Gastroenterol Nutr. 2019;69:581-587. doi:10.1097/MPG.0000000000002480

4. Furuta GT, Katzka DA. Eosinophilic esophagitis. N Engl J Med. 2015;373:1640-1648. doi:10.1056/NEJMra1502863

5. Navarro P, Arias A, Arias-Gonzalez L, et al. Systematic review with meta-analysis: the growing incidence and prevalence of eosinophilic oesophagitis in children and adults in population-based studies. Aliment Pharmacol Ther. 2019;49:1116-1125. doi:10.1111/apt.15231

6. O'Shea KM, Aceves SS, Dellon ES, et al. Pathophysiology of Eosinophilic Esophagitis. Gastroenterology. 2018;154:333-345. doi:10.1053/j. gastro.2017.06.065

7. Hirano I, Chan ES, Rank MA, et al. AGA institute and the joint task force on allergy-immunology practice parameters clinical guidelines for the management of eosinophilic esophagitis. Gastroenterology. 2020;158:1776-1786. doi:10.1053/j.gastro.2020.02.038

8. Furuta GT, Liacouras CA, Collins MH, et al. Eosinophilic esophagitis in children and adults: a systematic review and consensus recommendations for diagnosis and treatment. Gastroenterology. 2007;133:1342-1363. doi:10.1053/j.gastro.2007.08.017

9. Muir AB, Merves J, Liacouras CA. Role of endoscopy in diagnosis and management of pediatric eosinophilic esophagitis. Gastrointest Endosc Clin N Am. 2016;26:187-200. doi:10.1016/j.giec.2015.08.006

10. Friedlander JA, Fleischer DM, Black JO, et al. Unsedated transnasal esophagoscopy with virtual reality distraction enables earlier monitoring of dietary therapy in eosinophilic esophagitis. J Allergy Clin Immunol Pract. 2021;9:3494-3496. doi:10.1016/j.jaip.2021.06.030

11. Schoepfer AM, Safroneeva E, Bussmann C, et al. Delay in diagnosis of eosinophilic esophagitis increases risk for stricture formation in a timedependent manner. Gastroenterology. 2013;145:1230-6 e1-2. doi:10.1053/j.gastro.2013.08.015

12. Dellon ES, Kim HP, Sperry SL, et al. A phenotypic analysis shows that eosinophilic esophagitis is a progressive fibrostenotic disease. Gastrointest Endosc. 2014;79:577-85 e4. doi:10.1016/j.gie.2013.10.027

13. Attwood SE, Smyrk TC, Demeester TR, et al. Esophageal eosinophilia with dysphagia. A distinct clinicopathologic syndrome. Dig Dis Sci. 1993;38:109-116. doi:10.1007/BF01296781

14. Straumann A, Spichtin HP, Bernoulli R, et al. [Idiopathic eosinophilic esophagitis: a frequently overlooked disease with typical clinical aspects and discrete endoscopic findings]. Schweiz Med Wochenschr. 1994;124:1419-1429. German.

15. Kelly KJ, Lazenby AJ, Rowe PC, et al. Eosinophilic esophagitis attributed to gastroesophageal reflux: improvement with an amino acid-based formula. Gastroenterology. 1995;109:1503-1512. doi:10.1016/0016-5085(95)90637-1

16. Liacouras CA, Wenner WJ, Brown K, et al. Primary eosinophilic esophagitis in children: successful treatment with oral corticosteroids. $J$ Pediatr Gastroenterol Nutr. 1998;26:380-385. doi:10.1097/00005176-199804000-00004

17. Faubion WA, Perrault J, Burgart LJ, et al. Treatment of eosinophilic esophagitis with inhaled corticosteroids. J Pediatr Gastroenterol Nutr. 1998;27:90-93. doi:10.1097/00005176-199807000-00016

18. Dellon ES, Aderoju A, Woosley JT, et al. Variability in diagnostic criteria for eosinophilic esophagitis: a systematic review. Am J Gastroenterol. 2007;102:2300-2313. doi:10.1111/j.1572-0241.2007.01396.x

19. Ngo P, Furuta GT, Antonioli DA, et al. Eosinophils in the esophagus-peptic or allergic eosinophilic esophagitis? Case series of three patients with esophageal eosinophilia. Am J Gastroenterol. 2006;101:1666-1670. doi:10.1111/j.1572-0241.2006.00562.x

20. Dranove JE, Horn DS, Davis MA, et al. Predictors of response to proton pump inhibitor therapy among children with significant esophageal eosinophilia. J Pediatr. 2009;154:96-100. doi:10.1016/j.jpeds.2008.07.042 
21. Sayej WN, Patel R, Baker RD, et al. Treatment with high-dose proton pump inhibitors helps distinguish eosinophilic esophagitis from noneosinophilic esophagitis. J Pediatr Gastroenterol Nutr. 2009;49:393-399. doi:10.1097/MPG.0b013e31819c4b3e

22. Molina-Infante J, Ferrando-Lamana L, Ripoll C, et al. Esophageal eosinophilic infiltration responds to proton pump inhibition in most adults. Clin Gastroenterol Hepatol. 2011;9:110-117. doi:10.1016/j.cgh.2010.09.019

23. Dellon ES, Gonsalves N, Hirano I, et al. ACG clinical guideline: evidenced based approach to the diagnosis and management of esophageal eosinophilia and eosinophilic esophagitis (EoE). Am J Gastroenterol. 2013;108:679-92; quiz 693. doi:10.1038/ajg.2013.71

24. Liacouras CA, Furuta GT, Hirano I, et al. Eosinophilic esophagitis: updated consensus recommendations for children and adults. $J$ Allergy Clin Immunol. 2011;128:3-20 e6; quiz 21-2. doi:10.1016/j.jaci.2011.02.040

25. Rodrigo S, Abboud G, Oh D, et al. High intraepithelial eosinophil counts in esophageal squamous epithelium are not specific for eosinophilic esophagitis in adults. Am J Gastroenterol. 2008;103:435-442. doi:10.1111/j.1572-0241.2007.01594.x

26. Molina-Infante J, Lucendo AJ. Proton pump inhibitor therapy for eosinophilic esophagitis: a paradigm shift. Am J Gastroenterol. 2017;112:1770-1773. doi:10.1038/ajg.2017.404

27. Wen T, Dellon ES, Moawad FJ, et al. Transcriptome analysis of proton pump inhibitor-responsive esophageal eosinophilia reveals proton pump inhibitor-reversible allergic inflammation. J Allergy Clin Immunol. 2015;135:187-197. doi:10.1016/j.jaci.2014.08.043

28. Molina-Infante J, Bredenoord AJ, Cheng E, et al. Proton pump inhibitor-responsive oesophageal eosinophilia: an entity challenging current diagnostic criteria for eosinophilic oesophagitis. Gut. 2016;65:524-531. doi:10.1136/gutjnl-2015-310991

29. Sodikoff J, Hirano I. Proton pump inhibitor-responsive esophageal eosinophilia does not preclude food-responsive eosinophilic esophagitis. $J$ Allergy Clin Immunol. 2016;137:631-633. doi:10.1016/j.jaci.2015.07.008

30. Lucendo AJ, Molina-Infante J, Arias A, et al. Guidelines on eosinophilic esophagitis: evidence-based statements and recommendations for diagnosis and management in children and adults. United Eur Gastroenterol J. 2017;5:335-358. doi:10.1177/2050640616689525

31. Asher wolf W, Dellon ES. Eosinophilic esophagitis and proton pump inhibitors: controversies and implications for clinical practice. Gastroenterol Hepatol (N Y). 2014;10:427-432.

32. Spechler SJ, Genta RM, Souza RF. Thoughts on the complex relationship between gastroesophageal reflux disease and eosinophilic esophagitis. Am J Gastroenterol. 2007;102:1301-1306. doi:10.1111/j.1572-0241.2007.01179.x

33. Yoshida N, Yoshikawa T, Tanaka Y, et al. A new mechanism for anti-inflammatory actions of proton pump inhibitors-inhibitory effects on neutrophil-endothelial cell interactions. Aliment Pharmacol Ther. 2000;14(Suppl 1):74-81. doi:10.1046/j.1365-2036.2000.014s1074.x

34. Odiase E, Zhang X, Chang Y, et al. In esophageal squamous cells from eosinophilic esophagitis patients, Th2 cytokines increase eotaxin-3 secretion through effects on intracellular calcium and a non-gastric proton pump. Gastroenterology. 2021;160:2072-2088 e6. doi:10.1053/j. gastro.2021.02.016

35. Rochman M, Xie YM, Mack L, et al. Broad transcriptional response of the human esophageal epithelium to proton pump inhibitors. $J$ Allergy Clin Immunol. 2021;147:1924-1935. doi:10.1016/j.jaci.2020.09.039

36. Zhang X, Cheng E, Huo X, et al. Omeprazole blocks STAT6 binding to the eotaxin-3 promoter in eosinophilic esophagitis cells. PLoS One. 2012;7:e50037. doi:10.1371/journal.pone.0050037

37. Cheng E, Zhang X, Huo X, et al. Omeprazole blocks eotaxin-3 expression by oesophageal squamous cells from patients with eosinophilic oesophagitis and GORD. Gut. 2013;62:824-832. doi:10.1136/gutjnl-2012-302250

38. Caviglia R, Ribolsi M, Maggiano N, et al. Dilated intercellular spaces of esophageal epithelium in nonerosive reflux disease patients with physiological esophageal acid exposure. Am J Gastroenterol. 2005;100:543-548. doi:10.1111/j.1572-0241.2005.40978.x

39. Ravelli AM, Villanacci V, Ruzzenenti $\mathrm{N}$, et al. Dilated intercellular spaces: a major morphological feature of esophagitis. $J$ Pediatr Gastroenterol Nutr. 2006;42:510-515. doi:10.1097/01.mpg.0000215312.78664.b9

40. Solcia E, Villani L, Luinetti O, et al. Altered intercellular glycoconjugates and dilated intercellular spaces of esophageal epithelium in reflux disease. Virchows Arch. 2000;436:207-216. doi:10.1007/s004280050032

41. Tobey NA, Carson JL, Alkiek RA, et al. Dilated intercellular spaces: a morphological feature of acid reflux-damaged human esophageal epithelium. Gastroenterology. 1996;111:1200-1205. doi:10.1053/gast.1996.v111.pm8898633

42. Villanacci V, Grigolato PG, Cestari R, et al. Dilated intercellular spaces as markers of reflux disease: histology, semiquantitative score and morphometry upon light microscopy. Digestion. 2001;64:1-8. doi:10.1159/000048833

43. Blanchard C, Stucke EM, Burwinkel K, et al. Coordinate interaction between IL-13 and epithelial differentiation cluster genes in eosinophilic esophagitis. J Immunol. 2010;184:4033-4041. doi:10.4049/jimmunol.0903069

44. Souza RF, Huo X, Mittal V, et al. Gastroesophageal reflux might cause esophagitis through a cytokine-mediated mechanism rather than caustic acid injury. Gastroenterology. 2009;137:1776-1784. doi:10.1053/j.gastro.2009.07.055

45. Blevins CH, Sharma AN, Johnson ML, et al. Influence of reflux and central obesity on intercellular space diameter of esophageal squamous epithelium. United Eur Gastroenterol J. 2016;4:177-183. doi:10.1177/2050640615598426

46. Katzka DA, Ravi K, Geno DM, et al. Endoscopic mucosal impedance measurements correlate with eosinophilia and dilation of intercellular spaces in patients with eosinophilic esophagitis. Clin Gastroenterol Hepatol. 2015;13:1242-1248 e1. doi:10.1016/j.cgh.2014.12.032

47. Liu CC, Lee JW, Liu TT, et al. Relevance of ultrastructural alterations of intercellular junction morphology in inflamed human esophagus. $J$ Neurogastroenterol Motil. 2013;19:324-331. doi:10.5056/jnm.2013.19.3.324

48. Orlando LA, Orlando RC. Dilated intercellular spaces as a marker of GERD. Curr Gastroenterol Rep. 2009;11:190-194. doi:10.1007/s11894009-0030-6

49. Vela MF, Craft BM, Sharma N, et al. Refractory heartburn: comparison of intercellular space diameter in documented GERD vs. functional heartburn. Am J Gastroenterol. 2011;106:844-850. doi:10.1038/ajg.2010.476

50. Neumann H, Monkemuller K, Fry LC, et al. Intercellular space volume is mainly increased in the basal layer of esophageal squamous epithelium in patients with GERD. Dig Dis Sci. 2011;56:1404-1411. doi:10.1007/s10620-010-1458-0

51. Calabrese C, Fabbri A, Bortolotti M, et al. Dilated intercellular spaces as a marker of oesophageal damage: comparative results in gastrooesophageal reflux disease with or without bile reflux. Aliment Pharmacol Ther. 2003;18:525-532. doi:10.1046/j.1365-2036.2003.01713.x

52. Farre R, Blondeau K, Clement D, et al. Evaluation of oesophageal mucosa integrity by the intraluminal impedance technique. Gut. 2011;60:885-892. doi:10.1136/gut.2010.233049 
53. Xie C, Sifrim D, Li Y, et al. Esophageal baseline impedance reflects mucosal integrity and predicts symptomatic outcome with proton pump inhibitor treatment. J Neurogastroenterol Motil. 2018;24:43-50. doi:10.5056/jnm17032

54. Kessing BF, Bredenoord AJ, Weijenborg PW, et al. Esophageal acid exposure decreases intraluminal baseline impedance levels. Am $J$ Gastroenterol. 2011;106:2093-2097. doi:10.1038/ajg.2011.276

55. van Rhijn BD, Weijenborg PW, Verheij J, et al. Proton pump inhibitors partially restore mucosal integrity in patients with proton pump inhibitor-responsive esophageal eosinophilia but not eosinophilic esophagitis. Clin Gastroenterol Hepatol. 2014;12:1815-23 e2. doi:10.1016/j. cgh.2014.02.037

56. Lim LG, Neumann J, Hansen T, et al. Confocal endomicroscopy identifies loss of local barrier function in the duodenum of patients with Crohn's disease and ulcerative colitis. Inflamm Bowel Dis. 2014;20:892-900. doi:10.1097/MIB.0000000000000027

57. Marietta EV, Geno DM, Smyrk TC, et al. Presence of intraepithelial food antigen in patients with active eosinophilic oesophagitis. Aliment Pharmacol Ther. 2017;45:427-433. doi:10.1111/apt.13877

58. Ravi A, Marietta EV, Geno DM, et al. Penetration of the esophageal epithelium by dust mite antigen in patients with eosinophilic esophagitis. Gastroenterology. 2019;157:255-256. doi:10.1053/j.gastro.2019.02.042

59. Collins MH. Histopathologic features of eosinophilic esophagitis and eosinophilic gastrointestinal diseases. Gastroenterol Clin North Am. 2014;43:257-268. doi:10.1016/j.gtc.2014.02.007

60. Sherrill JD, Kc K, Wu D, et al. Desmoglein-1 regulates esophageal epithelial barrier function and immune responses in eosinophilic esophagitis Mucosal Immunol. 2014;7:718-729. doi:10.1038/mi.2013.90

61. Calabrese C, Bortolotti M, Fabbri A, et al. Reversibility of GERD ultrastructural alterations and relief of symptoms after omeprazole treatment. Am J Gastroenterol. 2005;100:537-542. doi:10.1111/j.1572-0241.2005.40476.x

62. Abdulnour-Nakhoul SM, Al-Tawil Y, Gyftopoulos AA, et al. Alterations in junctional proteins, inflammatory mediators and extracellular matrix molecules in eosinophilic esophagitis. Clin Immunol. 2013;148:265-278. doi:10.1016/j.clim.2013.05.004

63. Blevins CH, Iyer PG, Vela MF, et al. The esophageal epithelial barrier in health and disease. Clin Gastroenterol Hepatol. $2018 ; 16: 608-617$. doi:10.1016/j.cgh.2017.06.035

64. Zihni C, Mills C, Matter K, et al. Tight junctions: from simple barriers to multifunctional molecular gates. Nat Rev Mol Cell Biol. 2016;17:564580. doi:10.1038/nrm.2016.80

65. Tsukita S, Tanaka H, Tamura A. The claudins: from tight junctions to biological systems. Trends Biochem Sci. 2019;44:141-152. doi:10.1016/j. tibs.2018.09.008

66. Nguyen N, Fernando SD, Biette KA, et al. TGF-beta1 alters esophageal epithelial barrier function by attenuation of claudin-7 in eosinophilic esophagitis. Mucosal Immunol. 2018;11:415-426. doi:10.1038/mi.2017.72

67. D’Souza-Schorey C. Disassembling adherens junctions: breaking up is hard to do. Trends Cell Biol. 2005;15:19-26. doi:10.1016/j. tcb.2004.11.002

68. Green KJ, Jaiganesh A, Broussard JA. Desmosomes: essential contributors to an integrated intercellular junction network. F1000Res. 2019;8:2150. doi:10.12688/f1000research.20942.1

69. Politi E, Angelakopoulou A, Grapsa D, et al. Filaggrin and periostin expression is altered in eosinophilic esophagitis and normalized with treatment. J Pediatr Gastroenterol Nutr. 2017;65:47-52. doi:10.1097/MPG.0000000000001419

70. Jovov B, Que J, Tobey NA, et al. Role of E-cadherin in the pathogenesis of gastroesophageal reflux disease. Am $J$ Gastroenterol. 2011;106:1039-1047. doi:10.1038/ajg.2011.102

71. Davis BP. Pathophysiology of eosinophilic esophagitis. Clin Rev Allergy Immunol. 2018;55:19-42. doi:10.1007/s12016-017-8665-9

72. Frazzoni M, Penagini R, Frazzoni L, et al. Role of reflux in the pathogenesis of eosinophilic esophagitis: comprehensive appraisal with off- and on PPI impedance-ph monitoring. Am J Gastroenterol. 2019;114:1606-1613. doi:10.14309/ajg.0000000000000379

73. Roan F, Obata-Ninomiya K, Ziegler SF. Epithelial cell-derived cytokines: more than just signaling the alarm. J Clin Invest. 2019;129:14411451. doi:10.1172/JCI124606

74. Afonina IS, Zhong Z, Karin M, et al. Limiting inflammation-the negative regulation of NF-kappaB and the NLRP3 inflammasome. Nat Immunol. 2017;18:861-869. doi:10.1038/ni.3772

75. Erger RA, Casale TB. Interleukin-8 is a potent mediator of eosinophil chemotaxis through endothelium and epithelium. Am J Physiol. 1995;268: L117-22. doi:10.1152/ajplung.1995.268.1.L117

76. Rot A, Krieger M, Brunner T, et al. RANTES and macrophage inflammatory protein 1 alpha induce the migration and activation of normal human eosinophil granulocytes. J Exp Med. 1992;176:1489-1495. doi:10.1084/jem.176.6.1489

77. Fahey E, Doyle SL. IL-1 family cytokine regulation of vascular permeability and angiogenesis. Front Immunol. 2019;10:1426. doi:10.3389/ fimmu.2019.01426

78. Persad R, Huynh HQ, Hao L, et al. Angiogenic remodeling in pediatric EoE is associated with increased levels of VEGF-A, angiogenin, IL-8, and activation of the TNF-alpha-NFkappaB pathway. J Pediatr Gastroenterol Nutr. 2012;55:251-260. doi:10.1097/MPG.0b013e31824b6391

79. Barthel SR, Annis DS, Mosher DF, et al. Differential engagement of modules 1 and 4 of vascular cell adhesion molecule-1 (CD106) by integrins alpha4beta1 (CD49d/29) and alphaMbeta2 (CD11b/18) of eosinophils. J Biol Chem. 2006;281:32175-32187.

80. Min JY, Ocampo CJ, Stevens WW, et al. Proton pump inhibitors decrease eotaxin-3/CCL26 expression in patients with chronic rhinosinusitis with nasal polyps: possible role of the nongastric H,K-ATPase. J Allergy Clin Immunol. 2017;139:130-141 e11. doi:10.1016/j.jaci.2016.07.020

81. Uhlen M, Fagerberg L, Hallstrom BM, et al. Proteomics. Tissue-based map of the human proteome. Science. 2015;347:1260419. doi:10.1126/ science. 1260419

82. Kewley RJ, Whitelaw ML, Chapman-Smith A. The mammalian basic helix-loop-helix/PAS family of transcriptional regulators. Int J Biochem Cell Biol. 2004;36:189-204. doi:10.1016/S1357-2725(03)00211-5

83. Esser C, Rannug A, Ma Q. The aryl hydrocarbon receptor in barrier organ physiology, immunology, and toxicology. Pharmacol Rev. 2015;67:259-279. doi:10.1124/pr.114.009001

84. Fritsche E, Schafer C, Calles C, et al. Lightening up the UV response by identification of the arylhydrocarbon receptor as a cytoplasmatic target for ultraviolet B radiation. Proc Natl Acad Sci U S A. 2007;104:8851-8856. doi:10.1073/pnas.0701764104

85. Furue M, Hashimoto-Hachiya A, Tsuji G. Antioxidative phytochemicals accelerate epidermal terminal differentiation via the AHR-OVOL1 pathway: implications for atopic dermatitis. Acta Derm Venereol. 2018;98:918-923. doi:10.2340/00015555-3003 
86. Magiatis P, Pappas P, Gaitanis G, et al. Malassezia yeasts produce a collection of exceptionally potent activators of the Ah (dioxin) receptor detected in diseased human skin. J Invest Dermatol. 2013;133:2023-2030. doi:10.1038/jid.2013.92

87. Takei K, Mitoma C, Hashimoto-Hachiya A, et al. Antioxidant soybean tar Glyteer rescues T-helper-mediated downregulation of filaggrin expression via aryl hydrocarbon receptor. $J$ Dermatol. 2015;42:171-180. doi:10.1111/1346-8138.12717

88. Furue M, Tsuji G, Mitoma C, et al. Gene regulation of filaggrin and other skin barrier proteins via aryl hydrocarbon receptor. J Dermatol Sci. 2015;80:83-88. doi:10.1016/j.jdermsci.2015.07.011

89. Tsuji G, Hashimoto-Hachiya A, Kiyomatsu-Oda M, et al. Aryl hydrocarbon receptor activation restores filaggrin expression via OVOL1 in atopic dermatitis. Cell Death Dis. 2017;8:e2931. doi:10.1038/cddis.2017.322

90. van den Bogaard EH, Podolsky MA, Smits JP, et al. Genetic and pharmacological analysis identifies a physiological role for the AHR in epidermal differentiation. J Invest Dermatol. 2015;135:1320-1328. doi:10.1038/jid.2015.6

91. van den Bogaard EH, Bergboer JG, Vonk-Bergers M, et al. Coal tar induces AHR-dependent skin barrier repair in atopic dermatitis. $J$ Clin Invest. 2013;123:917-927. doi:10.1172/JCI65642

92. Rothhammer V, Quintana FJ. The aryl hydrocarbon receptor: an environmental sensor integrating immune responses in health and disease. Nat Rev Immunol. 2019;19:184-197. doi:10.1038/s41577-019-0125-8

93. Barroso A, Mahler JV, Fonseca-Castro PH, et al. The aryl hydrocarbon receptor and the gut-brain axis. Cell Mol Immunol. 2021;18(2):259-268. doi:10.1038/s41423-020-00585-5

94. Quattrochi LC, Tukey RH. Nuclear uptake of the Ah (dioxin) receptor in response to omeprazole: transcriptional activation of the human CYP1A1 gene. Mol Pharmacol. 1993;43:504-508.

95. Curi-Pedrosa R, Daujat M, Pichard L, et al. Omeprazole and lansoprazole are mixed inducers of CYP1A and CYP3A in human hepatocytes in primary culture. J Pharmacol Exp Ther. 1994;269:384-392.

96. Hu W, Sorrentino C, Denison MS, et al. Induction of cyp1a1 is a nonspecific biomarker of aryl hydrocarbon receptor activation: results of large scale screening of pharmaceuticals and toxicants in vivo and in vitro. Mol Pharmacol. 2007;71:1475-1486. doi:10.1124/mol.106.032748

97. Vinit C, Dieme A, Courbage S, et al. Eosinophilic esophagitis: pathophysiology, diagnosis, and management. Arch Pediatr. 2019;26:182-190. doi:10.1016/j.arcped.2019.02.005

98. Molina-Infante J, Rivas MD, Hernandez-Alonso M, et al. Proton pump inhibitor-responsive oesophageal eosinophilia correlates with downregulation of eotaxin-3 and Th2 cytokines overexpression. Aliment Pharmacol Ther. 2014;40:955-965. doi:10.1111/apt.12914

99. Park JY, Zhang X, Nguyen N, et al. Proton pump inhibitors decrease eotaxin-3 expression in the proximal esophagus of children with esophageal eosinophilia. PLoS One. 2014;9:e101391. doi:10.1371/journal.pone.0101391

100. Iwakura N, Fujiwara Y, Tanaka F, et al. Basophil infiltration in eosinophilic oesophagitis and proton pump inhibitor-responsive oesophageal eosinophilia. Aliment Pharmacol Ther. 2015;41:776-784. doi:10.1111/apt.13141

101. Bolton SM, Kagalwalla AF, Arva NC, et al. Mast cell infiltration is associated with persistent symptoms and endoscopic abnormalities despite resolution of eosinophilia in pediatric eosinophilic esophagitis. Am J Gastroenterol. 2020;115:224-233. doi:10.14309/ajg.0000000000000474

102. Kanagaratham C, El Ansari YS, Sallis BF, et al. Omeprazole inhibits IgE-mediated mast cell activation and allergic inflammation induced by ingested allergen in mice. J Allergy Clin Immunol. 2020;146:884-893 e5. doi:10.1016/j.jaci.2020.02.032

103. Lucendo AJ, Arias A, Molina-Infante J. Efficacy of proton pump inhibitor drugs for inducing clinical and histologic remission in patients with symptomatic esophageal eosinophilia: a systematic review and meta-analysis. Clin Gastroenterol Hepatol. 2016;14:13-22 e1. doi:10.1016/j. cgh.2015.07.041

104. Peterson KA, Thomas KL, Hilden K, et al. Comparison of esomeprazole to aerosolized, swallowed fluticasone for eosinophilic esophagitis. Dig Dis Sci. 2010;55:1313-1319. doi:10.1007/s10620-009-0859-4

105. Moawad FJ, Veerappan GR, Dias JA, et al. Randomized controlled trial comparing aerosolized swallowed fluticasone to esomeprazole for esophageal eosinophilia. Am J Gastroenterol. 2013;108:366-372. doi:10.1038/ajg.2012.443

106. Mangla S, Goldin AH, Singal G, et al. Endoscopic features and eosinophil density are associated with food impaction in adults with esophageal eosinophilia. Dig Dis Sci. 2016;61:2578-2584. doi:10.1007/s10620-016-4190-6

107. Dellon ES, Speck O, Woodward K, et al. Clinical and endoscopic characteristics do not reliably differentiate PPI-responsive esophageal eosinophilia and eosinophilic esophagitis in patients undergoing upper endoscopy: a prospective cohort study. Am J Gastroenterol. 2013;108:1854-1860. doi:10.1038/ajg.2013.363

108. Fujiwara Y, Sugawa T, Tanaka F, et al. A multicenter study on the prevalence of eosinophilic esophagitis and PPI-responsive esophageal eosinophilic infiltration. Intern Med. 2012;51:3235-3239. doi:10.2169/internalmedicine.51.8670

109. Francis DL, Foxx-Orenstein A, Arora AS, et al. Results of ambulatory pH monitoring do not reliably predict response to therapy in patients with eosinophilic oesophagitis. Aliment Pharmacol Ther. 2012;35:300-307. doi:10.1111/j.1365-2036.2011.04922.x

110. Vazquez-Elizondo G, Ngamruengphong S, Khrisna M, et al. The outcome of patients with oesophageal eosinophilic infiltration after an eightweek trial of a proton pump inhibitor. Aliment Pharmacol Ther. 2013;38:1312-1319. doi:10.1111/apt.12513

111. Martinek A, Spicak J, Spicak J, Spicak J, Spicak J. Treatment with proton pump inhibitors is effective in a majority of adults patients with eosinophilic esophagitis. Gastroenterology. 2013;144:S493. doi:10.1016/S0016-5085(13)61823-5

112. Gomez-Torrijos E, Garcia-Rodriguez R, Castro-Jimenez A, et al. The efficacy of step-down therapy in adult patients with proton pump inhibitor-responsive oesophageal eosinophilia. Aliment Pharmacol Ther. 2016;43:534-540. doi:10.1111/apt.13496

113. Philpott H, Nandurkar S, Royce SG, et al. A prospective open clinical trial of a proton pump inhibitor, elimination diet and/or budesonide for eosinophilic oesophagitis. Aliment Pharmacol Ther. 2016;43:985-993. doi:10.1111/apt.13576

114. DiGiovanni EL, Champeaux AL, Arroyo MR, et al. Esophageal eosinophilia treated with long-duration proton pump inhibitor therapy. $A C G$ Case Rep J. 2016;3:95-97. doi:10.14309/crj.2016.11

115. Potter JW, Saeian K, Staff D, et al. Eosinophilic esophagitis in adults: an emerging problem with unique esophageal features. Gastrointest Endosc. 2004;59:355-361. doi:10.1016/S0016-5107(03)02713-5

116. Nantes Castillejo O, Zozaya JM, Jimenez-Perez FJ, et al. [Incidence and characteristics of eosinophilic esophagitis in adults]. An Sist Sanit Navar. 2009;32:227-234. Spanish. doi:10.23938/ASSN.0161

117. Garrean CP, Zhang Q, Gonsalves N, et al. Acid reflux detection and symptom-reflux association using 4-day wireless $\mathrm{pH}$ recording combining 48-hour periods off and on PPI therapy. Am J Gastroenterol. 2008;103:1631-1637. doi:10.1111/j.1572-0241.2008.01829.x 
118. Jung YM, Lee HS, Lee DH, et al. [Clinical significance of incidentally detected eosinophilic esophagitis with pathologic review]. Korean $J$ Gastroenterol. 2010;55:162-168. Korean. doi:10.4166/kjg.2010.55.3.162

119. Abe Y, Iijima K, Ohara S, et al. A Japanese case series of 12 patients with esophageal eosinophilia. J Gastroenterol. 2011;46:25-30. doi:10.1007/s00535-010-0295-4

120. Levy AN, Rahaman SM, Bonis PA, et al. Hiccups as a presenting symptom of eosinophilic esophagitis. Case Rep Gastroenterol. 2012;6:340343. doi:10.1159/000338739

121. Tomomatsu Y, Yoshino J, Inui K, et al. Clinical features of eosinophilic esophagitis: ten Japanese cases. Dig Endosc. 2013;25:117-124. doi:10.1111/j.1443-1661.2012.01340.x

122. Lee JH, Kim MJ, Kim JH, et al. Clinical analysis of primary eosinophilic esophagitis. J Neurogastroenterol Motil. 2013;19:204-209. doi:10.5056/jnm.2013.19.2.204

123. Lipka S, Muhammad A, Champeaux A, et al. Case report of proton pump inhibitor responsive esophageal eosinophilia: why 2 months of proton pump inhibitors is required. Dis Esophagus. 2016;29:700-703. doi:10.1111/dote.12237

124. Ahn B, Lee DH, Lee CM, et al. [Proton pump inhibitor-responsive esophageal eosinophilia: an overview of cases from One University Hospital Center]. Korean J Gastroenterol. 2016;67:178-182. Korean. doi:10.4166/kjg.2016.67.4.178

125. Frazzoni M, Frazzoni L, De Bortoli N, et al. Response of eosinophilic oesophagitis to proton pump inhibitors is associated with impedance-pH parameters implying anti-reflux mechanism of action. Aliment Pharmacol Ther. 2021;53:1183-1189. doi:10.1111/apt.16371

126. Peterson KA, Yoshigi M, Hazel MW, et al. RNA sequencing confirms similarities between PPI-responsive oesophageal eosinophilia and eosinophilic oesophagitis. Aliment Pharmacol Ther. 2018;48:219-225. doi:10.1111/apt.14825

127. Laserna-Mendieta EJ, Casabona S, Guagnozzi D, et al. Efficacy of proton pump inhibitor therapy for eosinophilic oesophagitis in 630 patients: results from the EoE connect registry. Aliment Pharmacol Ther. 2020;52:798-807. doi:10.1111/apt.15957

128. Eke R, Li T, White A, et al. Systematic review of histological remission criteria in eosinophilic esophagitis. JGH Open. 2018;2:158-165. doi:10.1002/jgh3.12059

129. McElhiney J, Lohse MR, Arora AS, et al. The Mayo Dysphagia Questionnaire-30: documentation of reliability and validity of a tool for interventional trials in adults with esophageal disease. Dysphagia. 2010;25:221-230. doi:10.1007/s00455-009-9246-8

130. Laserna-Mendieta EJ, FitzGerald JA, Arias-Gonzalez L, et al. Esophageal microbiome in active eosinophilic esophagitis and changes induced by different therapies. Sci Rep. 2021;11:7113. doi:10.1038/s41598-021-86464-Z

131. Rank MA, Sharaf RN, Furuta GT, et al. Technical review on the management of eosinophilic esophagitis: a report from the AGA institute and the joint task force on allergy-immunology practice parameters. Gastroenterology. 2020;158:1789-1810 e15. doi:10.1053/j.gastro.2020.02.039

132. Sultan S, Falck-Ytter Y, Inadomi JM. The AGA institute process for developing clinical practice guidelines part one: grading the evidence. Clin Gastroenterol Hepatol. 2013;11:329-332. doi:10.1016/j.cgh.2013.02.001

133. Reed CC, Wolf WA, Cotton CC, et al. Optimal histologic cutpoints for treatment response in patients with eosinophilic esophagitis: analysis of data from a prospective cohort study. Clin Gastroenterol Hepatol. 2018;16:226-233 e2. doi:10.1016/j.cgh.2017.09.046

134. Molina-Infante J, Rodriguez-Sanchez J, Martinek J, et al. Long-term loss of response in proton pump inhibitor-responsive esophageal eosinophilia is uncommon and influenced by CYP2C19 genotype and rhinoconjunctivitis. Am J Gastroenterol. 2015;110:1567-1575. doi:10.1038/ajg.2015.314

135. Thakkar M, Keene S, Dellon ES, Dellon ES. Long-term outcomes and durability of response of proton pump inhibitor treatment in eosinophilic esophagitis. Gastroenterology. 2021;160:S-256:S-257. doi:10.1016/S0016-5085(21)01351-2

136. Agency for Healthcare Research and Quality. 2019 Prescribed Medicines. Medical Expenditure Panel Survey (MEPS). Rockville, MD: Agency for Healthcare Research and Quality; 2021.

137. Business Wire. Global Proton Pump Inhibitors Market to Surpass US\$ 3.5 Billion by 2027, Says Coherent Market Insights (CMI). Seattle, WA: Business Wire; 2020.

138. Yang YX, Metz DC. Safety of proton pump inhibitor exposure. Gastroenterology. 2010;139:1115-1127. doi:10.1053/j.gastro.2010.08.023

139. Brisebois S, Merati A, Giliberto JP. Proton pump inhibitors: review of reported risks and controversies. Laryngoscope Investig Otolaryngol. 2018;3:457-462. doi:10.1002/lio2.187

140. De Bruyne P, Ito S. Toxicity of long-term use of proton pump inhibitors in children. Arch Dis Child. 2018;103:78-82. doi:10.1136/archdischild2017-314026

141. Administration USFaD. FDA drug safety communication: Clostridium difficile associated diarrhea can be associated with stomach acid drugs known as proton pump inhibitors (PPIs). 2012.

142. Administration USFaD. FDA drug safety communication: possible increased risk of fractures of the hip, wrist, and spine with the use of proton pump inhibitors. 2011.

143. Administration USFaD. FDA drug safety communication: low magnesium levels can be associated with long-term use of Proton Pump Inhibitor drugs (PPIs), 2011.

144. Filion KB, Chateau D, Targownik LE, et al. Proton pump inhibitors and the risk of hospitalisation for community-acquired pneumonia: replicated cohort studies with meta-analysis. Gut. 2014;63:552-558. doi:10.1136/gutjnl-2013-304738

145. Giuliano C, Wilhelm SM, Kale-Pradhan PB. Are proton pump inhibitors associated with the development of community-acquired pneumonia? A meta-analysis. Expert Rev Clin Pharmacol. 2012;5:337-344. doi:10.1586/ecp.12.20

146. Nguyen PA, Islam M, Galvin CJ, et al. Meta-analysis of proton pump inhibitors induced risk of community-acquired pneumonia. Int $J$ Qual Health Care. 2020;32:292-299. doi:10.1093/intqhe/mzaa041

147. Wang $\mathrm{CH}$, Li CH, Hsieh R, et al. Proton pump inhibitors therapy and the risk of pneumonia: a systematic review and meta-analysis of randomized controlled trials and observational studies. Expert Opin Drug Saf. 2019;18:163-172. doi:10.1080/14740338.2019.1577820

148. Xun $\mathrm{X}$, Yin $\mathrm{Q}, \mathrm{Fu} \mathrm{Y}$, et al. Proton pump inhibitors and the risk of community-acquired pneumonia: an updated meta-analysis. Ann Pharmacother. 2021;10600280211039240. doi:10.1177/10600280211039240

149. Bavishi C, Dupont HL. Systematic review: the use of proton pump inhibitors and increased susceptibility to enteric infection. Aliment Pharmacol Ther. 2011;34:1269-1281. doi:10.1111/j.1365-2036.2011.04874.x

150. Hafiz RA, Wong C, Paynter S, et al. The risk of community-acquired enteric infection in proton pump inhibitor therapy: systematic review and meta-analysis. Ann Pharmacother. 2018;52:613-622. doi:10.1177/1060028018760569 
151. Vilcu AM, Sabatte L, Blanchon T, et al. Association between acute gastroenteritis and continuous use of proton pump inhibitors during winter periods of highest circulation of enteric viruses. JAMA Netw Open. 2019;2:e1916205. doi:10.1001/jamanetworkopen.2019.16205

152. Cheung KS, Leung WK. Long-term use of proton-pump inhibitors and risk of gastric cancer: a review of the current evidence. Therap Adv Gastroenterol. 2019;12:1756284819834511. doi:10.1177/1756284819834511

153. Li Z, Wu C, Li L, et al. Effect of long-term proton pump inhibitor administration on gastric mucosal atrophy: a meta-analysis. Saudi $J$ Gastroenterol. 2017;23:222-228. doi:10.4103/sjg.SJG_573_16

154. Abbas MK, Zaidi ARZ, Robert CA, et al. The safety of long-term daily usage of a proton pump inhibitor: a literature review. Cureus. 2019;11: e5563. doi: $10.7759 /$ cureus.5563

155. Vengrus CS, Delfino VD, Bignardi PR. Proton pump inhibitors use and risk of chronic kidney disease and end-stage renal disease: systematic review and meta-analysis. Minerva Urol Nephrol. 2021;73. doi:10.23736/S2724-6051.21.04116-3

156. Wijarnpreecha K, Thongprayoon C, Chesdachai S, et al. Associations of proton-pump inhibitors and h2 receptor antagonists with chronic kidney disease: a meta-analysis. Dig Dis Sci. 2017;62:2821-2827. doi:10.1007/s10620-017-4725-5

157. Hussain S, Singh A, Habib A, et al. Proton pump inhibitors use and risk of chronic kidney disease: evidence-based meta-analysis of observational studies. Clin Epidemiol Glob Health. 2019;7:46-52. doi:10.1016/j.cegh.2017.12.008

158. Nochaiwong S, Ruengorn C, Awiphan R, et al. The association between proton pump inhibitor use and the risk of adverse kidney outcomes: a systematic review and meta-analysis. Nephrol Dial Transplant. 2018;33:331-342. doi:10.1093/ndt/gfw470

159. Cheema E. Investigating the association of proton pump inhibitors with chronic kidney disease and its impact on clinical practice and future research: a review. J Pharm Policy Pract. 2019;12:6. doi:10.1186/s40545-019-0167-0

160. Peng CC, Tu YK, Lee GY, et al. Effects of proton pump inhibitors on glycemic control and incident diabetes: a systematic review and metaanalysis. J Clin Endocrinol Metab. 2021;106:3354-3366. doi:10.1210/clinem/dgab353

161. Sanchez-Garcia A, Simental-Mendia M, Simental-Mendia LE. Effect of proton-pump inhibitors on glucose and insulin metabolism on patients with type 2 diabetes: a systematic review and meta-analysis of randomized controlled trials. Curr Pharm Des. 2020;26:4007-4013. doi:10.2174/ 1381612826666200523170718

162. Janetzki JL, Sykes MJ, Ward MB, et al. Proton pump inhibitors may contribute to progression or development of chronic obstructive pulmonary disease-a sequence symmetry analysis approach. J Clin Pharm Ther. 2021;46:1687-1694. doi:10.1111/jcpt.13520

163. Kikuchi S, Imai H, Tani Y, et al. Proton pump inhibitors for chronic obstructive pulmonary disease. Cochrane Database Syst Rev. 2020;8: CD013113. doi:10.1002/14651858.CD013113.pub2

164. Desai M, Nutalapati V, Srinivasan S, et al. Proton pump inhibitors do not increase the risk of dementia: a systematic review and meta-analysis of prospective studies. Dis Esophagus. 2020;33. doi:10.1093/dote/doaa041

165. Zhang Y, Liang M, Sun C, et al. Proton pump inhibitors use and dementia risk: a meta-analysis of cohort studies. Eur J Clin Pharmacol. 2020;76:139-147. doi:10.1007/s00228-019-02753-7

166. Zhang Y, Zhan J, Bao Q, et al. Possible dementia risk of proton pump inhibitors and H2 receptor blockers use in the treatment of Helicobacter pylori: a meta-analysis study. Med Hypotheses. 2020;144:109989. doi:10.1016/j.mehy.2020.109989

167. Wijarnpreecha K, Thongprayoon C, Panjawatanan P, et al. Proton pump inhibitors and risk of dementia. Ann Transl Med. $2016 ; 4: 240$. doi:10.21037/atm.2016.06.14

168. Song YQ, Li Y, Zhang SL, et al. Proton pump inhibitor use does not increase dementia and Alzheimer's disease risk: an updated meta-analysis of published studies involving 642305 patients. PLoS One. 2019;14:e0219213. doi:10.1371/journal.pone.0219213

169. Khan MA, Yuan Y, Iqbal U, et al. No association linking short-term proton pump inhibitor use to dementia: systematic review and meta-analysis of observational studies. Am J Gastroenterol. 2020;115:671-678. doi:10.14309/ajg.0000000000000500

170. Huang B, Huang Y, Li Y, et al. Adverse cardiovascular effects of concomitant use of proton pump inhibitors and clopidogrel in patients with coronary artery disease: a systematic review and meta-analysis. Arch Med Res. 2012;43:212-224. doi:10.1016/j. arcmed.2012.04.004

171. Niu Q, Wang Z, Zhang Y, et al. Combination use of clopidogrel and proton pump inhibitors increases major adverse cardiovascular events in patients with coronary artery disease: a meta-analysis. J Cardiovasc Pharmacol Ther. 2017;22:142-152. doi:10.1177/1074248416663647

172. Hu W, Tong J, Kuang X, et al. Influence of proton pump inhibitors on clinical outcomes in coronary heart disease patients receiving aspirin and clopidogrel: a meta-analysis. Medicine (Baltimore). 2018;97:e9638. doi:10.1097/MD.0000000000009638

173. Sun S, Cui Z, Zhou M, et al. Proton pump inhibitor monotherapy and the risk of cardiovascular events in patients with gastro-esophageal reflux disease: a meta-analysis. Neurogastroenterol Motil. 2017;29:e12926. doi:10.1111/nmo.12926

174. Sherwood MW, Melloni C, Jones WS, et al. Individual proton pump inhibitors and outcomes in patients with coronary artery disease on dual antiplatelet therapy: a systematic review. J Am Heart Assoc. 2015;4. doi:10.1161/JAHA.115.002245

175. Juurlink DN, Dormuth CR, Huang A, et al. Proton pump inhibitors and the risk of adverse cardiac events. PLoS One. 2013;8:e84890. doi:10.1371/journal.pone.0084890

176. Moayyedi P, Eikelboom JW, Bosch J, et al. Safety of proton pump inhibitors based on a large, multi-year, randomized trial of patients receiving rivaroxaban or aspirin. Gastroenterology. 2019;157:682-691 e2. doi:10.1053/j.gastro.2019.05.056

177. Maggio M, Corsonello A, Ceda GP, et al. Proton pump inhibitors and risk of 1-year mortality and rehospitalization in older patients discharged from acute care hospitals. JAMA Intern Med. 2013;173:518-523. doi:10.1001/jamainternmed.2013.2851

178. Xie Y, Bowe B, Yan Y, et al. Estimates of all cause mortality and cause specific mortality associated with proton pump inhibitors among US veterans: cohort study. BMJ. 2019;365:11580. doi:10.1136/bmj.11580

179. Ben-Eltriki M, Green CJ, Maclure M, et al. Do proton pump inhibitors increase mortality? A systematic review and in-depth analysis of the evidence. Pharmacol Res Perspect. 2020;8:e00651. doi:10.1002/prp2.651

180. Brown JP, Tazare JR, Williamson E, et al. Proton pump inhibitors and risk of all-cause and cause-specific mortality: a cohort study. Br J Clin Pharmacol. 2021;87:3150-3161. doi:10.1111/bcp.14728

181. Freedberg DE, Kim LS, Yang YX. The risks and benefits of long-term use of proton pump inhibitors: expert review and best practice advice from the American Gastroenterological Association. Gastroenterology. 2017;152:706-715. doi:10.1053/j.gastro.2017.01.031

182. Jena AB, Sun E, Goldman DP. Confounding in the association of proton pump inhibitor use with risk of community-acquired pneumonia. $J$ Gen Intern Med. 2013;28:223-230. doi:10.1007/s11606-012-2211-5 
183. Freedberg DE, Abrams JA. Does confounding explain the association between PPIs and Clostridium difficile-related diarrhea? Am $J$ Gastroenterol. 2013;108:278-279. doi:10.1038/ajg.2012.395

184. Lima JJ, Thomas CD, Barbarino J, et al. Clinical Pharmacogenetics Implementation Consortium (CPIC) guideline for CYP2C19 and proton pump inhibitor dosing. Clin Pharmacol Ther. 2021;109:1417-1423. doi:10.1002/cpt.2015

185. Schroeder S, Capocelli KE, Masterson JC, et al. Effect of proton pump inhibitor on esophageal eosinophilia. J Pediatr Gastroenterol Nutr. 2013;56:166-172. doi:10.1097/MPG.0b013e3182716b7a

186. Rea F, Caldaro T, Tambucci R, et al. Eosinophilic esophagitis: is it also a surgical disease? J Pediatr Surg. 2013;48:304-308. doi:10.1016/j. jpedsurg.2012.11.006

187. Gutierrez-Junquera C, Fernandez-Fernandez S, Cilleruelo ML, et al. High prevalence of response to proton-pump inhibitor treatment in children with esophageal eosinophilia. J Pediatr Gastroenterol Nutr. 2016;62:704-710. doi:10.1097/MPG.0000000000001019

188. Gomez Torrijos E, Donado Palencia P, Sanchez Miranda MP, et al. Eosinophilic esophagitis: treatment with different doses of omeprazole in children under 16 years. J Investig Allergol Clin Immunol. 2018;28:191-192. doi:10.18176/jiaci.0230

189. Vieira GG, Ribeiro LBM, Truppel SK, et al. Endoscopic and histological characteristics in patients with eosinophilic esophagitis responsive and non-responsive to proton pump inhibitors. J Pediatr (Rio J). 2020;96:638-643. doi:10.1016/j.jped.2019.05.005

190. Dohil R, Newbury RO, Aceves S. Transient PPI responsive esophageal eosinophilia may be a clinical sub-phenotype of pediatric eosinophilic esophagitis. Dig Dis Sci. 2012;57:1413-1419. doi:10.1007/s10620-011-1991-5

191. Gutierrez-Junquera C, Fernandez-Fernandez S, Cilleruelo ML, et al. Long-term treatment with proton pump inhibitors is effective in children with eosinophilic esophagitis. J Pediatr Gastroenterol Nutr. 2018;67:210-216. doi:10.1097/MPG.0000000000001952

192. Schmidt E, Peiper U. [Influence of initial stretch on the dynamics of vascular smooth muscle]. Pflugers Arch. 1972;333:314-325. German. doi:10.1007/BF00586211

193. Barron JJ, Tan H, Spalding J, et al. Proton pump inhibitor utilization patterns in infants. J Pediatr Gastroenterol Nutr. $2007 ; 45: 421-427$. doi:10.1097/MPG.0b013e31812e0149

194. Blank ML, Parkin L. National study of off-label proton pump inhibitor use among New Zealand Infants in the first year of life (2005-2012). $J$ Pediatr Gastroenterol Nutr. 2017;65:179-184. doi:10.1097/MPG.0000000000001596

195. El Rouby N, Lima JJ, Johnson JA. Proton pump inhibitors: from CYP2C19 pharmacogenetics to precision medicine. Expert Opin Drug Metab Toxicol. 2018;14:447-460. doi:10.1080/17425255.2018.1461835

196. Kuhn BR, Young AJ, Justice AE, et al. Infant acid suppression use is associated with the development of eosinophilic esophagitis. Dis Esophagus. 2020;33. doi:10.1093/dote/doaa073

197. Jensen ET, Kuhl JT, Martin LJ, et al. Prenatal, intrapartum, and postnatal factors are associated with pediatric eosinophilic esophagitis. J Allergy Clin Immunol. 2018;141:214-222. doi:10.1016/j.jaci.2017.05.018

198. Canani RB, Cirillo P, Roggero P, et al. Therapy with gastric acidity inhibitors increases the risk of acute gastroenteritis and community-acquired pneumonia in children. Pediatrics. 2006;117:e817-20. doi:10.1542/peds.2005-1655

199. Rosen R, Vandenplas Y, Singendonk M, et al. Pediatric gastroesophageal reflux clinical practice guidelines: joint recommendations of the North American Society for Pediatric Gastroenterology, Hepatology, and Nutrition and the European Society for Pediatric Gastroenterology, Hepatology, and Nutrition. J Pediatr Gastroenterol Nutr. 2018;66:516-554. doi:10.1097/MPG.0000000000001889

200. Rosh JR, Hassall E. Therapy with gastric acidity inhibitors increases the risk of acute gastroenteritis and community-acquired pneumonia in children. J Pediatr Gastroenterol Nutr. 2006;43:545. doi:10.1097/01.mpg.0000239994.20270.a8

201. Lima JJ, Lang JE, Mougey EB, et al. Association of CYP2C19 polymorphisms and lansoprazole-associated respiratory adverse effects in children. J Pediatr. 2013;163:686-691. doi:10.1016/j.jpeds.2013.03.017

202. Wechsler JB, Hirano I. Biological therapies for eosinophilic gastrointestinal diseases. J Allergy Clin Immunol. 2018;142:24-31 e2. doi:10.1016/ j.jaci.2018.05.018

203. Ko E, Chehade M. Biological therapies for eosinophilic esophagitis: where do we stand? Clin Rev Allergy Immunol. 2018;55:205-216. doi:10.1007/s12016-018-8674-3

204. Huang C, Chen L, Savage SR, et al. Proteogenomic insights into the biology and treatment of HPV-negative head and neck squamous cell carcinoma. Cancer Cell. 2021;39:361-379 e16. doi:10.1016/j.ccell.2020.12.007

205. Relling MV, Schwab M, Whirl-Carrillo M, et al. Clinical pharmacogenetics implementation consortium guideline for thiopurine dosing based on TPMT and NUDT15 genotypes: 2018 update. Clin Pharmacol Ther. 2019;105:1095-1105. doi:10.1002/cpt.1304

206. Shoda T, Wen T, Aceves SS, et al. Eosinophilic oesophagitis endotype classification by molecular, clinical, and histopathological analyses: a cross-sectional study. Lancet Gastroenterol Hepatol. 2018;3:477-488. doi:10.1016/S2468-1253(18)30096-7

207. Canas JA, Tabares A, Barbero C, et al. Proton-pump inhibitor response prediction using esophageal microRNAs in children with eosinophilic esophagitis. J Pediatr Gastroenterol Nutr. 2020;71:755-763. doi:10.1097/MPG.0000000000002957

208. Cicali EJ, Blake K, Gong Y, et al. Novel implementation of genotype-guided proton pump inhibitor medication therapy in children: a pilot, randomized, multisite pragmatic trial. Clin Transl Sci. 2019;12:172-179. doi:10.1111/cts.12589

209. Jensen ET, Dellon ES. Environmental factors and eosinophilic esophagitis. J Allergy Clin Immunol. 2018;142:32-40. doi:10.1016/j. jaci.2018.04.015

210. Viechtbauer W. Conducting meta-analyses in R with the metafor package. J Stat Softw. 2010;36:1-48. doi:10.18637/jss.v036.i03

211. Garrean CP, Patil D, Gonsalves N, et al. S1860 comparison of endoscopic and histologic response in patients with eosinophilic esophagitis treated with proton pump inhibition, topical fluticasone, and dietary elimination. Gastroenterology. 2009;136:A-279. doi:10.1016/S0016-5085(09)61275-0

212. Mangla S, Singal G, Hornick JL, et al. Su1866 clinical predictors of response to proton pump inhibitors in patients with esophageal eosinophilia. Gastroenterology. 2013;144:S-495-S-496. doi:10.1016/S0016-5085(13)61831-4

213. Harris BR, Hon E, Gupta SK. Implementation of guidelines in eosinophilic esophagitis at an academic pediatric practice. Dis Esophagus. 2018;31. doi:10.1093/dote/doy029

214. Rosen I, Mahamed A, Garah J, et al. The management and course of eosinophilic oesophagitis in Israeli children. Acta Paediatr. 2021;110:1653-1657. doi:10.1111/apa.15746

215. Shoda T, Matsuda A, Nomura I, et al. Eosinophilic esophagitis versus proton pump inhibitor-responsive esophageal eosinophilia: transcriptome analysis. J Allergy Clin Immunol. 2017;139:2010-2013 e4. doi:10.1016/j.jaci.2016.11.028 
216. Moawad FJ, Wells JM, Johnson RL, et al. Comparison of eotaxin-3 biomarker in patients with eosinophilic oesophagitis, proton pump inhibitorresponsive oesophageal eosinophilia and gastro-oesophageal reflux disease. Aliment Pharmacol Ther. 2015;42:231-238. doi:10.1111/apt.13258

217. Votto M, De Filippo M, Castagnoli R, et al. Non-invasive biomarkers of eosinophilic esophagitis. Acta Biomed. 2021;92:e2021530. doi:10.23750/abm.v92iS7.12401

\section{Publish your work in this journal}

The Journal of Asthma and Allergy is an international, peer-reviewed open-access journal publishing original research, reports, editorials and commentaries on the following topics: Asthma; Pulmonary physiology; Asthma related clinical health; Clinical immunology and the immunological basis of disease; Pharmacological interventions and new therapies. The manuscript management system is completely online and includes a very quick and fair peer-review system, which is all easy to use. Visit http://www.dovepress.com/testimonials.php to read real quotes from published authors.

Submit your manuscript here: https://www.dovepress.com/journal-of-asthma-and-allergy-journal 